TITLE:

\title{
Multiple colonizations of Lake Biwa by Sarcocheilichthys fishes and their population history
}

$\operatorname{AUTHOR}(S)$ :

Komiya, Takefumi; Fujita-Yanagibayashi, Sari; Watanabe, Katsutoshi

\section{CITATION:}

Komiya, Takefumi ...[et al]. Multiple colonizations of Lake Biwa by Sarcocheilichthys fishes and their population history. Environmental Biology of Fishes 2014, 97(7): 741-755

\section{ISSUE DATE:}

2014-07

URL:

http://hdl.handle.net/2433/199855

\section{RIGHT:}

The final publication is available at Springer via http://dx.doi.org/10.1007/s10641-0130176-9.; この論文は出版社版でありません。引用の際には出版社版をご確認ご利用くだ さい。; This is not the published version. Please cite only the published version. 
2 Multiple colonizations of Lake Biwa by Sarcocheilichthys fishes and their

\section{3 population history}

4

5

Takefumi Komiya $\cdot$ Sari Fujita-Yanagibayashi $\cdot$ Katsutoshi Watanabe

7

8

9 T. Komiya $\cdot$ S. Fujita-Yanagibayashi $\cdot$ K. Watanabe $(*)$

10 Division of Biological Science, Graduate School of Science, Kyoto University,

11 Kitashirakawa-Oiwakecho, Sakyo-ku, Kyoto 606-8502, Japan

12 e-mail: watanak@terra.zool.kyoto-u.ac.jp, takefumi.komiya@gmail.com

13

14

15

16

17

18

19

20

21

22

23

24

25

26

*Corresponding author: Katsutoshi Watanabe, Division of Biological Science, Graduate

School of Science, Kyoto University, Kitashirakawa-Oiwakecho, Sakyo-ku, Kyoto 606-8502, Japan; Phone\&Fax +81-75-753-4079; e-mail: watanak@terra.zool.kyoto-u.ac.jp

Type of paper: Original paper

Suggested running title: Multiple colonization by Lake Biwa gudgeons

3 Text 23 pp., 6 Figs., 3 Tables, 4 ESM Tables 
27 Abstract Rapid adaptation and speciation have not been well documented for organisms in

28 Lake Biwa, Japan, the oldest ancient lake in East Asia. To examine these processes, we

29 focused on the divergence of Sarcocheilichthys gudgeons and conducted phylogeographic and

30

31

32

33 along with environmental changes.

44

45 Phylogeography $\cdot$ Trophic polymorphism population genetic analyses using mitochondrial DNA sequences and microsatellite data. No remarkable genetic differentiation was found between two species, S. biwaensis and $S$. variegatus microoculus, both endemic to Lake Biwa, whereas this species group, including $S$. v. variegatus, was genetically divided into three major regional groups: the Lake Biwa, Ise Bay, and western groups. Divergent mtDNA haplotypes were included within the Lake Biwa and western groups, strongly suggesting secondary contacts among allopatrically isolated populations. Dating for mtDNA phylogeny using a geological constraint suggested the colonization of Lake Biwa by multiple Sarcocheilichthys lineages that diverged from each other in the early-middle Pleistocene. Coalescent-based population analyses indicated that the local populations colonized the rocky bottom habitat in Lake Biwa from other habitats after the Last Glacial Maximum, likely reflecting past environmental changes in the lake, including the disappearance of rocky areas during the glacial climate. Divergent morphological adaptation in Sarcocheilichthys associated with substrate type may have rapidly proceeded

5 Keywords Ancient lake $\cdot$ Central Japan · Gobioninae $\cdot$ Historical demography 
Organisms that colonized novel environments often show ecological divergence in resource use, accompanied by morphological and physiological adaptations (Schluter 2000; Losos 2010). Such adaptation phenomena are important to understanding the roles of natural selection in species diversification. Physically isolated environments such as oceanic islands and lakes provide robust geographical systems to study adaptive evolution and speciation (Schluter 2000; Losos and Ricklefs 2009). For example, animal assemblages in ancient lakes such as the African Great Lakes and Lake Baikal in Siberia have been studied as typical cases of adaptive radiation, which involve long geological history, diversified environmental settings, and isolation from neighboring habitats to various extents (Martens 1997; Cristescu et al. 2010). On the other hand, rapid adaptive evolution and speciation, such as following the colonization of post-glacial lakes, are also important processes to elucidate the role of divergent natural selection in species diversification (e.g., Schluter 1998; Hudson et al. 2011). Such colonization-adaptation processes as those observed in post-glacial lakes may have repeatedly occurred along with environmental changes during historical radiation in ancient lakes. To understand the patterns of colonization-adaptation processes over a wide time scale and the formation of resultant endemic assemblages, phylogenetic and phylogeographic information of constituent species must be accumulated and compared. $\left(35^{\circ} 20^{\prime} \mathrm{N}, 136^{\circ} 10^{\prime} \mathrm{E}, 84.4 \mathrm{~m}\right.$ above sea level). It is the largest lake in Japan in terms of surface area $\left(670.3 \mathrm{~km}^{2}\right)$ and volume $\left(27.5 \mathrm{~km}^{3}\right)$ and is also the oldest lake in East Asia, dating to 4 million years ago (Mya) (Yokoyama 1984; Kawabe 1994). Similar to other ancient lakes,

71 Lake Biwa harbors many animal and plant species $(>1,000)$, including about 70 fish

72 species/subspecies (Nishino 2003; Nishino and Hamabata 2005). Not surprisingly, the lake has been recognized as a focal research area for biodiversity and speciation of freshwater 
organisms in Japan (Kawanabe 1978, 1996; Rossiter 2000). However, the number ( 60) and proportion $(<10 \%)$ of endemic species/subspecies are not very large when compared to levels of endemism in other ancient lakes throughout the world (e.g., $>600$ species in Lake Tanganyika; 1,000 species in Lake Baikal; Martens 1997). Sixteen endemic/semi-endemic fish species ( $\sim 24 \%$ of total) belonging to 12 genera of six families occur in Lake Biwa; this phylogenetic diversity also characterizes the fish assemblage in this lake (Watanabe, in press). The organisms endemic to Lake Biwa generally exhibit distinct adaptations to the particular environments of the lake (e.g., the extensive pelagic area, deep zone, or rocky substrate), which started to be formed in the mid-Pleistocene ( 0.4 Mya; "the present Lake Biwa"; Yokoyama 1984; Kawabe 1989, 1994; Meyers et al. 1993). The endemic organisms are often divided into two categories: species that evolved in the lake and relic species (Kawanabe 1978, 1996). Among these, the former are presumed to have differentiated from their ancestors through ecological adaptation after the formation of the present lake environments (e.g., Tomoda 1978; Takahashi 1989). However, recent molecular phylogenetic studies have revealed that several endemic cyprinids and a goby, that have typically been considered adapted to the lake, were derived from their closest relatives much earlier (in the Pliocene-early Pleistocene) than the formation of the present environments (Harada et al. 2002; Takada et al. 2010; Kakioka et al. 2013; Tabata and Watanabe 2013). In these cases, the ecological and morphological adaptations are inferred to have occurred much more recently than the divergence of the endemic lineages. In contrast, some endemic forms occur that exhibit adaptive ecological/morphological divergences without distinct genetic differentiation from their relatives living in or around the lake. Representatives of such species are the gudgeons of the genus Sarcocheilichthys (Cyprinidae: Cypriniformes), which exhibit trophic and body color polymorphisms (Komiya et al. 2011).

Sarcocheilichthys variegatus microoculus and Sarcocheilichthys biwaensis are endemic to Lake Biwa and are presumed to have evolved from the ancestral riverine species $S$. 
100 variegatus variegatus (distributed widely in western Japan except Lake Biwa) via divergent

101 adaptation to various local environments of the lake (Hosoya 1982). Trophic polymorphisms

102 in their head and mouth shape clearly correspond to variation in the bottom environment

103 (pebbly vs. rocky). Although not enough data are available, some genetic variation possibly

104 contributes to their morphological variation (Nakamura 1969; Komiya et al., unpublished

105 data). However, genetic analysis using presumably neutral markers (microsatellites) has not

106 revealed any significant differentiation among local populations within or between the species

107 in Lake Biwa (Komiya et al. 2011). Then, this case may represent an example of rapid

108 adaptation and speciation in Lake Biwa, which have not yet been documented for organisms

109 in this lake.

110 To estimate the spatiotemporal pattern of adaptive divergence of the Sarcocheilichthys

111 fishes in Lake Biwa, their history of colonization and demography in Lake Biwa must be

112 characterized. For this purpose, we conducted phylogeographic and population demographic

113 analyses of population samples collected from the entire distribution of Sarcocheilichthys

114 species in Japan using mitochondrial DNA and microsatellite markers. Our results suggest

115 multiple colonization events of Lake Biwa by these species as well as their recent settlement

116 and adaptation to a novel environment. On the basis of the estimated history of this group, the

117 origins of the endemic species and their adaptation in Lake Biwa are discussed.

Materials and methods

Specimen collection

124 Fish samples of Sarcocheilichthys variegatus variegatus, S. v. microoculus, and S. biwaensis

125 were collected from 28 localities throughout the entire range of these species in Japan (Fig. 1; 
126 Table 1). Before selecting the local samples outside the Lake Biwa basin, we excluded

127 locations that included specimens obviously identified as $S$. v. microoculus by morphological

128 characteristics (Hosoya 1982), as this endemic Lake Biwa subspecies has been introduced

129 into several regions contaminated with fishery stocking of Ayu, Plecoglossus altivelis, from

130 Lake Biwa (e.g., Kurita et al. 2012; Watanabe 2012).

131 The localities were geographically grouped into five regions: Lake Biwa, Ise Bay, Kinki,

132 Chugoku, and Kyushu (Table 1). Almost all specimens were from wild populations, collected

133 by gill-net and dip-net, or purchased from local fishermen, with the exception of one local

134 sample of S. biwaensis (locality code \#14; part), which was obtained from a captive

135 population that has been kept in the Lake Biwa Museum, Shiga, Japan, since 1995 or later

136 (Table 1). The bottom environments of the sampling sites in Lake Biwa were categorized into

137 rocky or pebbly (Fig. 1; Nishino 1991). Specimens from Lake Biwa include those used by

138 Komiya et al. (2011).

139

140

MtDNA sequencing and analyses

141

A total of 344 specimens from 26 localities, including 249 specimens from 15 sites in/around

Lake Biwa, were used for the mtDNA analysis (Table 1). Total genomic DNA was isolated

144 from fin clips preserved in $100 \%$ ethanol using a Genomic DNA Purification Kit (Promega,

145 Madison, WI, USA). Polymerase chain reaction (PCR) amplification was performed using the 146 primer pair L14724 (5'-TGA CTT GAA RAA CCA YCG YYG-3') (Palumbi et al. 1991) and 147 H15915 (5'-ACC TCC GAT CTY CGG ATT ACA AGA C-3') (Aoyama et al. 2000) to

148 obtain the nucleotide sequences of the 3 '-half of the mitochondrial cytochrome $b$ gene (cyt $b$;

149620 base pairs, bp). The PCR conditions and sequencing method were the same as those

150 described by Komiya et al. (2011). The obtained sequences were deposited in the DNA Data

151 Bank of Japan (DDBJ), GenBank, and European Nucleotide Archive (EMBL) (accession 
152

153

154

155

156

157

158

159

160

161

162

163

164

165

166

167

168

169

170

171

172

173

174

175

176

177

numbers AB601449-601470, AB780978-780997). The haplotype frequencies of each population were deposited in the Genetic Diversity and Distribution Map (GEDIMAP) freshwater fish database (http://gedimap.zool.kyoto-u.ac.jp; Watanabe et al. 2010a) with population IDs P1279-1290, P1292-1296, and P1691-1705.

Genetic diversity indices, i.e., the number of haplotypes, haplotype diversity, and

nucleotide diversity, were calculated for each region group using ARLEQUIN v3.5 (Excoffier and Lischer 2010). Haplotype richness, an analogue to allelic richness, was also calculated using the rarefaction method (Kalinowski 2004). Genetic differentiation among local samples was assessed by pairwise $F_{\mathrm{ST}}$, calculated for samples with $\geq 8$ specimens using ARLEQUIN. The significance level (0.05) for multiple comparisons was corrected using the sequential Bonferroni method (Holm 1979; Rice 1989). A statistical parsimony network was constructed using TCS v1.2.1 (Clement et al. 2000) at a $90 \%$ confidence limit for the mtDNA haplotypes obtained.

A Bayesian approach was used to estimate the phylogenetic tree and the divergence times of lineages using the GTR + I model, selected by the Bayesian information criterion (BIC) in jModeltest v2.1.1 (Darriba et al. 2012), and the Yule (speciation) tree prior using BEAST v1.7.4 (Drummond and Rambaut 2007). Referring to the gobionine phylogeny proposed by Tang et al. (2011), the following four outgroup sequences were added to the analysis: Sarcocheilichthys kiangsiensis (AY952984; Yang et al. 2006), S. nigripinnis (JN003319; Tang et al. 2011), S. soldatovi (JN003337; Tang et al. 2011), and S. czerskii (EF193433; Zhang et al. 2008). We adopted the random local clock model, which assumes one or more independent rates on different branches (Drummond and Suchard 2010). To estimate the time of the most recent common ancestors (tMRCA), a geological constraint, i.e., the uplift of the Suzuka Mountains in central Honshu Island 1.0-1.5 Mya (Yokoyama 1988; Kawabe 1994), was applied for the relevant node age. The constraint was specified as a lognormal prior distribution, ranging from approximately 1.1 to 1.5 Mya in the $95 \%$ range 
178 with mean $=1.3 \mathrm{Mya}, \log (\mathrm{SD})=0.1$, and offset $=0$. All other model parameters used default

179 priors. For each Markov-chain Monte Carlo (MCMC) analysis, we performed two

180 independent runs of 50 million generations. We sampled every 1000 th generation and

181 removed $10 \%$ of the initial samples as burn-in. The convergence of the chains to the

182 stationary distribution and large effective sample size (ESS; $>200)$ were confirmed using

183 TRACER v1.5 (Rambaut and Drummond 2009). The consensus tree was calculated using

184 LogCombiner v1.6.2 and TreeAnnotator v1.6.2 in the BEAST package, and the tree was

185 visualized using FigTree v1.3.1 (Rambaut 2009).

186 To estimate the demographic history of Sarcocheilichthys fishes in Lake Biwa, we 187 applied a Bayesian skyline plot (BSP) analysis (Drummond et al. 2005) for the mtDNA data, 188 implemented in BEAST. All Lake Biwa specimen data were combined $(n=242)$, but distinct 189 haplotype groups were analyzed separately or in combination. We performed two independent 190 runs with an MCMC chain length of 50 or 500 million generations, and their convergence to 191 the stationary distribution and large ESS (>200) were confirmed using TRACER. We sampled every 1000th generation and removed $10 \%$ of the initial samples as burn-in. The substitution model was selected using the BIC in jModeltest. The time to expansion was estimated using the mutation rate obtained in the Bayesian phylogenetic analysis similar to the above analysis but using only ingroup haplotypes [normal prior distribution, mean = $0.0122 /$ million years $(\mathrm{Myr}), \log (\mathrm{SD})=0.0032$, covering $0.0070-0.0175 / \mathrm{Myr}$ in the $95 \%$

197 range; see "Results"]. The BSP results with the stepwise (constant) model were summarized 198 using Tracer.

Demographic parameters for pooled and respective local samples were also estimated 200 based on mismatch distributions of pairwise differences (Rogers and Harpending 1992). The

201 fitness of the observed data to a model of either sudden population expansion (Rogers and 202 Harpending 1992) or spatial expansion (Schneider and Excoffier 1999) was tested using 203 ARLEQUIN. We conducted neutrality tests by calculating Tajima's $D$ (Tajima 1989) and 
204 Fu's $F_{\mathrm{S}}(\mathrm{Fu}$ 1997) to explore the demographic change, using ARLEQUIN. The significance

205 for all the estimates was tested by 10,000 permutations.

206

207 Microsatellite analyses

208

209 A total of 254 specimens from 15 localities, including 153 S. v. microoculus and 28 S.

210 biwaensis specimens from 10 sites in/around Lake Biwa and 73 S. v. variegatus from 5 sites

211 in western Japan, were used for the microsatellite analysis (Table 1). A total of 14

212 microsatellite loci isolated from S. v. microoculus (Fujita et al. 2008) were analyzed,

213 including 13 dinucleotide repeats (Svm03, Svm10, Svm32, Svm34, Svm46, Svm48, Svm49,

214 Svm50, Svm53, Svm56, Svm72, Svm82, and Svm166) and one trinucleotide repeat (Svm51).

215 PCR conditions for each locus were described by Fujita et al. (2008). PCR products were

216 sized on an automated DNA sequencer (ABI Prism GA310; Applied Biosystems, Foster City,

217 CA, USA) using GeneScan v3.1 and ROX400HD as the size standard (Applied Biosystems).

218 The mean observed $\left(H_{\mathrm{O}}\right)$ and expected $\left(H_{\mathrm{E}}\right)$ heterozygosities of the microsatellite data

219 and their deviation from Hardy-Weinberg equilibrium were analyzed using ARLEQUIN

220 [Electronic supplementary material (ESM) Table S1]. The pairwise $F_{\text {ST }}$ was calculated to test

221 the differentiation among local samples using ARLEQUIN. A Bayesian clustering approach,

222 implemented in STRUCTURE v2.3.4 (Pritchard et al. 2000), was used to estimate the

223 population structure. Ten replicates for each predefined $K=1-16$ were obtained with runs of

224100,000 burn-in and 1,000,000 MCMC iterations, applying the admixture model with

225 correlated alleles. To determine the most likely value of $K$, the method of Evanno et al. (2005)

226 was implemented in the program STRUCTURE HARVESTER (Earl and vonHoldt 2012),

227 which determines the second-order rate of change in the distribution of $\mathrm{L}(K)$.

228 The migration and demographic histories of the Sarcocheilichthys fishes within Lake

229 Biwa were estimated using Migrate-n v3.3.2 (Beerli and Felsenstein 1999, 2001). To estimate 
230 pairwise migration rates among 12 site/species samples and the tMRCA of each sample, we

231 employed a Brownian motion approximation of the stepwise mutation model. The mutation

232 rates were treated as variable among loci, and pairwise geographic distances among sites (as

233 coastal distances) were given for the analysis (ESM Table S2). Two independent runs

$234(1,000,000$ burn-in steps followed by 5,000,000 steps sampled every 100 steps) were

235 conducted.

\section{Results}

Population structure and divergence time

242 In total, 42 mtDNA haplotypes were detected from 344 specimens of the Japanese

243 Sarcocheilichthys fishes, and of these, 24 haplotypes were obtained from Lake Biwa (Table 2;

244 Fig. 2). The haplotype tree revealed five major clades (A-E) (Fig. 3). Three of these (A, B, 245 and C) were found in Lake Biwa, resulting in moderately high genetic diversity (Table 2; Figs.

246 2, 3). Clade A was dominant, with $71 \%$ of individuals (89\% in Lake Biwa) possessing 247 haplotypes in this clade. Clade A haplotypes were shared by S. variegatus and S. biwaensis 248 and were represented by a star-like network with haplotype A01 as the central and dominant 249 (73\%) haplotype (Fig. 2). A subclade of clade A, consisting of A15 and A16, and a tip 250 haplotype, A18, were detected exclusively from the Chugoku region. Clade B haplotypes 251 were obtained from the Lake Biwa, Kinki, and Chugoku regions, but showed some regional 252 distribution patterns. The most interior haplotype of clade $\mathrm{C}(\mathrm{C} 03)$ was exclusively found in 253 Kyushu, but the tip haplotypes were shared by specimens from the Lake Biwa, Kinki, and 254 Chugoku regions. Clade D was endemic to the Yura River system (Kinki), and clade E was 255 the earliest divergent group and was endemic to the Ise Bay area (Figs. 2, 3). 
The divergence times among the five major mtDNA clades (A-E) were estimated to be

257

258

259

260

261

262

263

264

265

266

267 $0.62-1.26 \mathrm{Myr}$ [lower and upper limits of $95 \%$ highest probability density (HPD), $0.29-1.51$ Myr; Table 3; Fig. 3]. The three clades occurring in Lake Biwa (A, B, and C) were suggested to have differentiated from each other (tMRCA, 0.75-0.81 Myr, $95 \%$ HPD, 0.38-1.29 Myr) before the formation of the present Lake Biwa environments ( $\sim 0.4$ Mya).

In terms of $F_{\mathrm{ST}}$, almost all sample pairs from different regions showed significant differentiation for both mtDNA and microsatellites, but almost no differentiation was found between $S$. v. microoculus and S. biwaensis (all 15 comparisons in mtDNA and 18 of 20 comparisons in microsatellites; ESM Table S3). In the microsatellite data, the assignment analysis supported the division into three population groups (the maximum $\Delta K=19.03$ at $K=$ 3), basically corresponding to the regional samples from the Lake Biwa, Ise Bay, and western populations including the Kinki, Chugoku, and Kyushu samples (Fig. 4). Again, S. v.

microoculus and S. biwaensis were clustered into the single "Lake Biwa" population. Some of the Yura River specimens were assigned to the Lake Biwa population, and this sample included three loci exhibiting deviation from Hardy-Weinberg equilibrium (ESM Table S1); they may be attributable to artificial introductions.

\section{Population demography and migration in Lake Biwa}

The mutation rate of the mtDNA cyt $b$ segment was estimated at $0.0122 / \mathrm{Myr} /$ lineage $(95 \%$ HPD, 0.0069-0.0180) by the Bayesian phylogenetic analysis using only the Japanese Sarcocheilichthys data. Using this mutation rate and its approximate credibility range (see "Materials and methods"), the demographic history of the Lake Biwa population was estimated using the BSP analyses for all mtDNA haplotypes and respective haplotype clades (Fig. 5). The BSP results indicated that the recent population expansion started 0.05 Mya or later (i.e., during the last glacial period). This expansion pattern was obvious in the analyses 
282 using all haplotypes and only the clade A haplotypes. This was also supported by neutrality

283 tests using Tajima's $D$ and Fu's $F_{\mathrm{S}}($ all $P<0.05$ ), and partially supported by mismatch

284 distribution analysis (departure from the sudden expansion model or spatial expansion model, $285 \quad P>0.05 ;$ ESM Table S4).

The historical migration rates estimated by microsatellite data showed asymmetric

287 patterns among sites (Fig. 6a). The tendency of unidirectional immigration to rocky bottom

288 areas (Loc. \#7 and 14) was remarkable (Fig. 6b). The tMRCAs of the rocky local populations

289 (average, 0.67/mutation/generation), with the exception of S. v. microoculus in Loc. \#13, were 290 clearly shorter (0.1-0.4 times, $0.26 \pm 0.13 \mathrm{SD}$ times on average) than those of the other 291 populations $(2.61 \pm 0.06 /$ mutation/generation; Fig. $6 c)$.

\section{Discussion}

Population structure of the Sarcocheilichthys fishes and multiple colonizations of Lake Biwa

Our microsatellite data revealed the regional population structure of the Japanese

Sarcocheilichthys fishes, and these results were also supported by mtDNA data. In particular, the mtDNA tree showed that the fishes are differentiated into two major regional groups that are divided by the Suzuka Mountains. These findings suggest that these two groups have been isolated since the mountain system was formed 1.0-1.5 Mya (Yokoyama 1988; Kawabe 303 1994), and the western group expanding from Lake Biwa to Kyushu Island experienced gene

304 flow within this time scale. Considering that the western group includes two species $(S$.

305 biwaensis and S. variegatus) with two subspecies (S. v. variegatus and S. v. microoculus)

306 (Hosoya 1982, 2001), the unique population group in the Ise Bay area, east of the Suzuka 307 Mountains, could be treated as a unique taxonomic and conservation unit. Detailed 
morphological/taxonomic reexaminations will be necessary.

In the area west of the Suzuka Mountains, except for Kyushu, largely diverged mtDNA haplotypes were detected within regional population groups or even within local samples, which were represented as single genetic groups by clustering analysis with microsatellite data. Some exceptional specimens in the Yura River sample fully or partially exhibited genetic characteristics of the Lake Biwa specimens in both microsatellite and mtDNA data. This pattern would be attributable to an artificial introduction because Lake Biwa fishes including S. v. microoculus are well known to have been introduced into several regions, admixed with fishery stocking of Ayu from Lake Biwa (e.g., Kurita et al. 2012; Watanabe 2012). In the other localities, however, the occurrence of diverged mtDNA suggests historical secondary contacts among differentiated populations through multiple dispersal events by, for example, the connections of river systems (Avise 2000).

In samples from Lake Biwa, divergent mtDNA haplotypes from three distinct clades were detected, each exhibiting moderate genetic diversity. Even taking the large credibility intervals into consideration, it is highly probable that the divergence among the three clades (A, B, and C; $95 \% \mathrm{HPD}, 0.38-1.29 \mathrm{Myr}$ ), at least that of $\mathrm{C}$ from the others (0.46-1.29 Myr), preceded the formation of the present environments of the northern Lake Biwa basin, which harbors a large, deep pelagic zone and rocky shore/bottom ( $\sim .4$ Mya). Considering the heterogeneous distribution patterns of the mtDNA clades together, these results strongly suggest multiple colonization events of Lake Biwa by the Sarcocheilichthys fishes, following allopatric population differentiation.

Common or closely related haplotypes occurring in both Lake Biwa and the Kinki-Chugoku regions around the Seto Inland Sea suggest some historical gene flow among these regions. Such gene flow would be possible, at least partially, during marine regression periods when river systems in these regions would have interconnected owing to desiccation of the Seto Inland Sea (31 m water depth on average at present; Yonekura et al. 2001). 
334 Regional freshwater fish fauna (Tsubokawa 1988; Watanabe 2012) and phylogeographic

335 patterns of some other fish species also support such riverine connections; i.e., the

336 populations around Seto Inland Sea share close mtDNA haplotypes, for example, in Medaka

337 Oryzias latipes, the cyprinid Biwia zezera and Gnathopogon elongatus, respectively

338 (Takehana et al. 2003; Watanabe et al. 2010b; Kakioka et al. 2013). The observed genetic

339 diversity pattern in the Sarcocheilichthys fishes reflects such a geographical history associated

340 with the formation processes of freshwater fauna in western Japan. Lake Biwa would have

341 served as a pool accepting colonizers at multiple time scales and preserving their genetic

342 diversity, and also as a source for dispersal to neighboring areas.

344 Colonization and demographic history in Lake Biwa and the origin of adaptation

346 The Sarcocheilichthys fishes in Lake Biwa exhibit remarkable, continuous variation in head 347 shape from short to long (Nakamura 1969; Hosoya 1982; Tomoda 1991). As in other fishes

348 (Smith and Skúlason 1996), the head shape divergence is associated with diverse habitats and 349 feeding habits in this group and is thus considered a trophic polymorphism (Komiya et al.

350 2011, unpublished data). Sarcocheilichthys variegatus microoculus includes short,

351 intermediate, and long head types, which occur in sandy, pebbly, and rocky bottom habitats, 352 respectively. Sarcocheilichthys biwaensis is the long head extreme form inhabiting rocky 353 bottom areas (Hosoya 1982; Tomoda 1991; Komiya et al. 2011). The longer headed

354 individuals from rocky areas are equipped with a narrow head, elongated mouth, large jaw, 355 and large, anteriorly positioned eyes. In addition, they have a deep and laterally compressed 356 body. All of these traits are considered to be advantageous for handling attached and/or 357 cryptic prey in crevices in the rocky bottom or floating in open water (Komiya et al. 2011; 358 unpublished data). Because the rocky bottom habitat is unique within the species' range and is 359 restricted even in Lake Biwa, the long head type of $S$. v. microoculus and S. biwaensis was 
very likely derived from ancestral shorter head forms.

The head shape divergence could be caused by phenotypic plasticity, genetic differences, or a combination of both. Despite the remarkable morphological differences, there was no distinct genetic differentiation between the short and long head samples or even between $S$. v. microoculus and S. biwaensis in presumably neutral genetic markers (Komiya et al. 2011; present study). However, Nakamura's (1969) brief description and our unpublished result of experimental breeding suggest that the head shape variation in this group is genetically controlled to some extent. These facts imply a short history of divergence and/or partial gene flow among these forms and species.

The more detailed, coalescent-based analysis revealed intriguing patterns of migration and establishment of the local Sarcocheilichthys populations within Lake Biwa. The detected unidirectional immigration patterns to the rocky bottom areas were consistent with the hypothesis of the recent establishment of local populations in the rocky habitat. Their shorter estimated tMRCAs also support this idea. Geological and paleoclimatic studies have indicated that the water level of the lake was lowered (about $-30 \mathrm{~m}$ ) and the rocky bottom environment almost disappeared during the last glacial period, which was mainly associated with low precipitation (Uemura and Yokoyama 1983; Ishida et al. 1984). The absolute ages of the tMRCAs are difficult to estimate because of the uncertainty associated with the mutation rates of our microsatellite markers. However, if the population expansion of the entire Lake Biwa population occurred about 0.05 Mya or later, as estimated by the mtDNA BSP analysis, the rocky habitat populations, with tMRCAs one-fourth shorter than the others, may have established later than 0.02 Mya, i.e., after the Last Glacial Maximum (LGM; 0.02 Mya). This pattern implies that the rocky $S$. v. microoculus and S. biwaensis populations proceeded to colonize and establish in re-emerged rocky environments as temperatures rose and precipitation increased after the LGM. The shortest tMRCA for the S. biwaensis population in Loc. \#14, however, could be a result of a founder effect and/or bottleneck in this captive 
386 population. On the other hand, the larger tMRCA of the rocky S. v. microoculus around

387 Okishima Island (Loc. \#13) may be because the rocky environment around the island appears 388 to have exceptionally remained even during the last glacial period owing to the position and 389 geology of the island (Uemura and Yokoyama 1983; Ishida et al. 1984). The morphological characteristics of the rocky populations are inferred to be strongly

391 linked to the rocky bottom environments as mentioned above. Thus, such traits are supposed 392 to have adaptively evolved along with colonization of the rocky areas, probably after the 393 LGM. This also suggests the rapid speciation of S. biwaensis from an ancestral S. $v$.

394 microoculus form. These patterns support the hypothesis that divergent adaptive evolution has 395 been recurrently occurring even in the fish assemblage in Lake Biwa in the absence of 396 explosive adaptive radiation. To prove their rapid evolution and speciation, the genetic 397 contribution to the adaptive traits and the intensity of reproductive isolation between the two 398 species must be examined in detail.

399 In contrast with the cases of several Lake Biwa endemics whose origins are inferred to 400 precede the formation of the present Lake Biwa environments ( 0.4 Mya; e.g., Kakioka et al. 401 2013; Tabata and Watanabe 2013), the probable rapid adaptation/speciation inferred for the 402 Sarcocheilichthys fishes is a rare known case in Lake Biwa and represents an ideal candidate 403 for the study of divergent adaptation in Lake Biwa. Their multiple colonization history over 404 several hundred thousand years implies an accumulation of genetic variation in their genome 405 for adapting to the various environmental conditions that appeared in the Paleo-Lake Biwa. 406 Such standing variation may have played an important role in the rapid adaptation of this 407 group. Recently developed genomic methods (see, e.g., Gilad et al. 2009; Schoville et al. 408 2012) will be applied to further elucidate the genetic basis and evolutionary dynamics of the 409 flexible adaptation of these fishes, including their trophic polymorphisms. 
412 Acknowledgments We express sincere thanks to professional fishermen of Lake Biwa for

413 cooperation in fish sampling, to Lake Biwa Museum, Shiga Prefecture, for the kind

414 permission to use stocking samples, to S. Kanao, J. Nakajima, C. Oshiumi and J. Kitamura for 415 providing fish samples, and to K. Hosoya, T. Kokita, R. Kakioka, M. Nishida, H. Takeshima, 416 M. Hori and the members of Laboratory of Animal Ecology of Kyoto University for their 417 valuable advice during this study. This study was supported by the Grants-in-Aid from the 418 Ministry of Education, Culture, Sports, Science, and Technology, Japan (nos. 18570086, 419 21370035, Biodiversity Research of the 21st Century COE: A14, and "Formation of a 420 Strategic Base for Biodiversity and Evolutionary Research: from Genome to Ecosystem" of 421 the GCOE), the Core Stage Backup Research Fund of Kyoto University, and the Foundation 422 of Ito Grant for Ichthyology, Fujiwara Natural History Foundation. This study complies with 423 current laws in Japan and the Regulation on Animal Experimentation at Kyoto University.

\section{References}

Aoyama J, Watanabe S, Ishikawa S, Nishida M, Tsukamoto K (2000) Are morphological characters distinctive enough to discriminate between two species of freshwater eels, Anguilla celebesensis and A. interioris? Ichthyol Res 47:157-161

Avise JC (2000) Phylogeography: the history and formation of species. Harvard University Press, Cambridge

Beerli P, Felsenstein J (1999) Maximum-likelihood estimation of migration rates and effective population numbers in two populations using a coalescent approach. Genetics $152: 763-773$

Beerli P, Felsenstein J (2001) Maximum likelihood estimation of a migration matrix and effective population sizes in $\mathrm{n}$ subpopulations by using a coalescent approach. Proc Nat 
439 Clement M, Posada D, Crandall KA (2000) TCS: A computer program to estimate gene genealogies. Mol Ecol 9:1657-1659

Cristescu ME, Adamowicz SJ, Vaillant JJ, Haffner DG (2010) Ancient lakes revisited: from the ecology to the genetics of speciation. Mol Ecol 19:4837-4851

Darriba D, Taboada GL, Doallo R, Posada D (2012) jModelTest 2: more models, new heuristics and parallel computing. Nat Methods 9:772

Drummond AJ, Rambaut A (2007) BEAST: Bayesian evolutionary analysis by sampling trees. BMC Evol Biol 7:214

Drummond AJ, Suchard MA (2010) Bayesian random local clocks, or one rate to rule them all. BMC Biol 8:114

Drummond AJ, Rambaut A, Shapiro B, Pybus OG (2005) Bayesian coalescent inference of past population dynamics from molecular sequences. Mol Biol Evol 22:1185-1192

Earl DA, vonHoldt BM (2012) STRUCTURE HARVESTER: a website and program for visualizing STRUCTURE output and implementing the Evanno method. Conserv Genet Resour 4:359-361

Evanno G, Regnaut S, Goudet J (2005) Detecting the number of clusters of individuals using the software STRUCTURE: a simulation study. Mol Ecol 14:2611-2620

Excoffier L, Lischer HEL (2010) Arlequin suite ver 3.5: a new series of programs to perform population genetics analyses under Linux and Windows. Mol Ecol Resour 10:564-567

Fu YX (1997) Statistical tests of neutrality of mutations against population growth, hitchhiking, and background selection. Genetics 147:915-925

460 Fujita S, Komiya T, Takeshima H, Watanabe K, Nishida M (2008) Isolation and characterization of 15 microsatellite loci for the Japanese gudgeon Sarcocheilichthys

463 Gilad Y, Pritchard JK, Thornton K (2009) Characterizing natural variation using 
next-generation sequencing technologies. Trends Genet 25:463-471

465

466

467

Harada S, Jeon SR, Kinoshita I, Tanaka M, Nishida M (2002) Phylogenetic relationships of four species of floating gobies (Gymnogobius) as inferred from partial mitochondrial cytochrome $b$ gene sequences. Ichthyol Res 49:324-332

Holm S (1979) A simple sequentially rejective multiple test procedure. Scand J Statist $6: 65-70$

Hosoya K (1982) Classification of the cyprinid genus Sarcocheilichthys from Japan, with description of a new species. Jpn J Ichthyol 29:127-138

Hosoya K (2001) Higai, genus Sarcocheilichthys. In: Kawanabe H, Mizuno N, Hosoya K (eds) Freshwater fishes of Japan. Yama-Kei Publishers, Tokyo, pp 310-313 (in Japanese)

Hudson AG, Vonlanthen P, Seehausen O (2011) Rapid parallel adaptive radiations from a single hybridogenic ancestral population. Proc R Soc B:278:58-66

Ishida S., Kawada K, Miyamura M (1984) Geology of the Hikone-seibu district. Chiiki chishitsu kenkyu hokoku, scale 1:50,000 Kyoto (11), no 17, Chishitsu Chosajo (in Japanese with English summary)

Kakioka R, Kokita T, Tabata R, Mori S, Watanabe K (2013) The origins of limnetic forms and cryptic divergence in Gnathopogon fishes (Cyprinidae) in Japan. Environ Biol Fish $96: 631-644$

Kalinowski ST (2004) Counting alleles with rarefaction: private alleles and hierarchical sampling designs. Conserv Genet 5:539-543

Kawabe T (1989) Stratigraphy of the lower part of the Kobiwako group around the Ueno Basin, Kinki District, Japan. J Geosci, Osaka City Univ 32:39-52

Kawabe T (1994) Chapter 1. Biwako no Oitachi (formation of Lake Biwa). In: Research Group for Natural History of Lake Biwa (ed) Biwako no Shizenshi (The natural history of Lake Biwa). Yasaka Shobo, Tokyo, pp 24-72 (in Japanese)

Kawanabe H (1978) Some biological problems. Verh Internat Ver Limnol 20:2674-2677 
490 Kawanabe H (1996) Asian great lakes, especially Lake Biwa. Environ Biol Fish 47:219-234

491 Komiya T, Fujita S, Watanabe K (2011) A novel resource polymorphism in fish, driven by differential bottom environments: an example from an ancient lake in Japan. PLoS One 6:e17430

Kurita Y, Nakajima J, Inui R (2012) Host mussels of the introduced Lake Biwa endemic, Sarcocheilichthys variegatus microoculus (Cyprinidae), in northern Kyushu Island, Japan. Jpn J Ichthyol 59:95-97 (in Japanese)

Losos JB (2010) Adaptive radiation, ecological opportunity, and evolutionary determinism. Am Nat 175:623-639

Losos JB, Ricklefs RE (2009) Adaptation and diversification on islands. Nature 457:830-836

Martens K (1997) Speciation in ancient lakes. Trends Ecol Evol 12:177-182

Meyers PA, Takemura K, Horie S (1993) Reinterpretation of late Quaternary sediment chronology of Lake Biwa, Japan, from correlation with marine glacial-interglacial cycles. Quatern Res 39:154-162

Nakamura M (1969) Cyprinid fishes of Japan: studies on the life history of cyprinid fishes of Japan. Research Institute for Natural Resources, Tokyo (in Japanese).

Nishino M (1991) Regional division of the lake shore based on benthic animals. In: Lake Biwa Environmental Research Institute (ed) Project Report (No 90-A05): Research Institute, Otsu, pp 47-63 (in Japanese)

Nishino M (2003) Biwako no Koyushu wo Meguru Mondai. Koyushu list no Ichibu Shusei nit suite (The problem of endemics in Lake Biwa). Oumia 76:3-4 (in Japanese)

Nishino M, Hamabata E (2005) Naiko karano Message [The message from "Naiko (lagoon around Lake Biwa)’]. Sun-rise Press, Shiga (in Japanese)

514 Palumbi S, Martin A, Romano S, McMillian WO, Stice, et al. (1991) The simple fool's guide to PCR. Hawaii University Press, Honolulu 
516 Pritchard JK, Stephens M, Donnelly P (2000) Inference of population structure using multilocus genotype data. Genetics 155:945-959

518 Rambaut A (2009) FigTree Version 1.3.1. http://tree.bio. ed.ac.uk/software/figtree/

519 Rambaut A, Drummond AJ (2009) Tracer version 1.5. http:// tree.bio.ed.ac.uk/software/tracer/

521 Rice WR (1989) Analyzing tables of statistical tests. Evolution 43:223-225

522 Rogers AR, Harpending H (1992) Population growth makes waxes in the distribution of pairwise genetic differences. Mol Biol Evol 9:552-569

524 Rossiter A (2000) Lake Biwa as a topical ancient Lake. Adv Ecol Res 31:571-598

Schluter D (1998) Ecological speciation in postglacial fishes. In: Grant PR (ed) Evolution on islands. Oxford University Press, Oxford, pp 163-180

Schluter D (2000) Ecology of adaptive radiation. Oxford University Press, Oxford

Schneider S, Excoffier L (1999) Estimation of demographic parameters from the distribution of pairwise differences when the mutation rates vary among sites: application to human mitochondrial DNA. Genetics 152:1079-1089

531 Schoville SD, Bonin A, François O, Lobreaux S, Melodelima C, Manel S (2012) Adaptive genetic variation on the landscape: methods and cases. Ann Rev Ecol Evol Syst 43:23-43

533 Smith TB, Skúlason S (1996) Evolutionary significance of resource polymorphisms in fishes, amphibians, and birds. Annu Rev Ecol Syst 27:111-133

Tabata R, Watanabe K (2013) Hidden mitochondrial DNA divergence in the Lake Biwa endemic goby Gymnogobius isaza: implications for its evolutionary history. Environ Biol Fish 96:701-702

538 Tajima F (1989) Statistical method for testing the neutral mutation hypothesis by DNA $539 \quad$ polymorphism. Genetics $123: 585-595$

540 Takada M, Tachihara K, Kon T, Yamamoto G, Iguchi K, Miya M, Nishida M (2010) 541 Biogeography and evolution of the Carassius auratus-complex in East Asia. BMC 
543 Takahashi S (1988) A review of the origins of endemic species in Lake Biwa with special

544 reference to the goby fish, Chaenogobius isaza. J Paleolimnol 1:279-292

545 Takehana Y, Nagai N, Matsuda M, Tsuchiya K, Sakaizumi M (2003) Geographic variation

546 and diversity of the cytochrome $b$ gene in Japanese wild populations of medaka, Oryzias

$547 \quad$ latipes. Zool Sci 20:1279-1291

548 Tang KL, Agnew MK, Chen WJ, Vincent Hirt M, Raley ME, Sado T, Schneider LM, Yang L,

549 Bart HL, He S, Liu H, Miya M, Saitoh K, Simons AM, Wood RM, Mayden RL (2011)

550 Phylogeny of the gudgeons (Teleostei: Cyprinidae: Gobioninae). Mol Phylogenet Evol

$551 \quad 61: 103-124$

552 Tomoda Y (1978) Biwako to Namazu (Lake Biwa and catfish). Chobunsha, Tokyo (in $553 \quad$ Japanese)

554 Tomoda Y (1991) Fish of Lake Biwa: endemic fish of Lake Biwa and fish remains collected 555 from Paleo Lake Biwa (Kobiwako Group). In: the Editorial Committee of Natural 556 History of Shiga Prefecture (ed) Natural history of Shiga Prefecture: a report of comprehensive academic study. Foundation of Nature Conservation of Shiga Prefecture, Otsu, pp 1399-1457 (in Japanese with English abstract)

Tsubokawa K (1988) Zoogeographical consideration on the freshwater fish fauna of the Okayama Region, Japan. Bull Kurashiki Mus Nat Hist 3:1-30 (in Japanese with English abstract)

Uemura Y, Yokoyama T (1983) Biwako no shizen — chikei to chisou · chishitsu (Nature of Lake Biwa — topography, stratigraphy, and geology). Bewako-henshu-iinkai (ed) Biwako sono shizen to shakai (Lake Biwa, its nature and society). Sun Bright Publ, Otsu, pp 39-52 (in Japanese)

Watanabe K (2012) Faunal structure of Japanese freshwater fishes and its artificial disturbance. Environ Biol Fish 94:533-547 
568 Watanabe (in press) Origin and diversification of freshwater fishes in Lake Biwa. In: Okuda N (ed) Biodiversity in aquatic systems and environments: in Lake Biwa. Springer, Tokyo

Watanabe K, Kano Y, Takahashi T, Mukai T, Kakioka R, Tominaga K (2010a) GEDIMAP: a database of genetic diversity for Japanese freshwater fishes. Ichthyol Res 57:107-109

Watanabe K, Kawase S, Mukai T, Kakioka R, Miyazaki J-I, Hosoya K (2010b) Population divergence of Biwia zezera (Cyprinidae: Gobioninae) and the discovery of a cryptic species, based on mitochondrial and nuclear DNA sequence analyses. Zool Sci $27: 647-655$

Yang JQ, He SP, Freyhof J, Witte K, Liu HZ (2006) The phylogenetic relationships of the Gobioninae (Teleostei: Cyprinidae) inferred from mitochondrial cytochrome $b$ gene sequences. Hydrobiologia 553:255-266

Yokoyama T (1984) Stratigraphy of the quaternary system around Lake Biwa and geohistory of the ancient Lake Biwa. In: Horie S (ed) Lake Biwa, monographiae biologicae (volume 54). Dr W Junk Publishers, Dordrecht, pp 43-128

Yokoyama T (1988) Seinan Nihon no Shizenshi (Natural history of southwestern Japan). Sanwa-shobo, Kyoto (in Japanese)

584 Yonekura N, Kaizuka S, Nogami M, Chinzai K (2001) Regional geomorphology of the Japanese Islands, vol 1 Introduction to Japanese geomorphology. University of Tokyo Press, Tokyo (in Japanese)

Zhang L, Tang QY, Liu HZ (2008) Phylogeny and speciation of the eastern Asian cyprinid genus Sarcocheilichthys. J Fish Biol 72:1122-1137 
Fig. 1 Sampling localities of Sarcocheilichthys fishes. Numbers correspond to those in Table

1. Triangles, S. biwaensis; circles, S. variegatus microoculus; squares, S. v. variegatus. *

Fig. 2 Statistical parsimony network for mtDNA cyt $b$ haplotypes of the Japanese

Sarcocheilichthys fishes. The areas of the circles containing a haplotype number are proportional to haplotype frequency (but shown as a half for A01). Haplotypes are separated by colors that correspond to species and localities, as depicted in the pie graph. $S b, S$. biwaensis; Svm, S. variegatus microoculus; Svv, S. variegatus variegatus. The dashed line

601 indicates an alternative connection (loop). The closed small circles indicate unobserved 602 hypothetical haplotypes.

603

Fig. 3 Bayesian phylogenetic tree of Sarcocheilichthys fishes based on partial mtDNA cytochrome $b$ sequences with the GTR + I model. The tree was dated using the random local clock model with a node age constraint [ $C s$ a lognormal prior distribution with mean $=1.3$ Mya, $\log (\mathrm{SD})=0.1$, and offset $=0]$. Numbers at nodes indicate Bayesian posterior probabilities (values $<80 \%$ not shown). Horizontal bars at nodes show credibility intervals as 95\% HPD. Species and locality where the haplotype was detected are shown as filled squares on the right side of the tree. Abbreviations: Sb, S. biwaensis; Svm, S. variegatus microoculus;

$611 S v v, S$. variegatus variegatus; $I B$, Ise Bay; $K K$, Kinki; $C G$, Chugoku; $K S$, Kyushu. Haplotype 612 codes are the same as those in Fig. 2. Node numbers shown in a circle correspond to those in 613 Table 3

615 Fig. 4 Bayesian assignment analysis of Sarcocheilichthys samples based on microsatellite 
616 data using STRUCTURE (Pritchard et al. 2000). a $\Delta K$ following Evanno et al. (2005) as a

617 function of the number of assumed populations $(K=1-17)$. b Results of the assignment for $K$

$618=3$. Each vertical bar represents an individual partitioned into the three clusters defined by

619 STRUCTURE. Abbreviations: Sb, S. biwaensis; Svm, S. variegatus microoculus; Svv, S.

620 variegatus variegatus; $I B$, Ise Bay; $K K$, Kinki; $C G$, Chugoku; $K S$, Kyushu. Sample codes

621 correspond to those in Fig. 1 and Table 1

622

623 Fig. 5 Bayesian skyline plots for Sarcocheilichthys fishes in Lake Biwa for all haplotypes

$624(A l l)$ and for each clade of haplotypes $(A-C)$. The central bold line represents the mean value 625 for the relative effective female population size, and the shaded area denotes the $95 \%$ HPD

627 Fig. 6 The historical migration patterns and tMRCAs for local populations of

628 Sarcocheilichthys fishes in Lake Biwa estimated using Migrate-n (Beerli and Felsenstein

629 1999, 2001). Sample codes correspond to those in Fig. 1 and Table $1.7 b$ and $14 b$ are $S$.

630 biwaensis samples; others are $S$. variegatus microoculus. * Rocky bottom area, ** including

631 both rocky and pebbly areas, and others pebbly areas. a Pairwise migration rate matrix [M, as

632 immigration rate/(mutation rate $\times \mathrm{km})]$. Darker squares indicate higher migration rates. $\mathbf{b}$

633 Major migration patterns among local populations. Only migration links to neighboring sites

634 are indicated. Closed triangles, S. biwaensis; closed circles, S. v. microoculus. c Mean

635 tMRCAs for local populations as scaled in mutation/generation. Horizontal lines indicate

636 standard deviation

637 
Table 1 Localities and sample size of Sarcocheilichthys fishes analyzed

\begin{tabular}{|c|c|c|c|c|c|c|}
\hline Locality code & Locality (bottom type) & Species & mtDNA & Microsatellite & Remarks $^{a}$ & GEDIMAP ID \\
\hline \multicolumn{7}{|l|}{ Lake Biwa } \\
\hline & 1 Off Kitakomatsu, Otsu, Shiga (P) & Svm & - & 15 & P8 & \\
\hline & 2 Yotsu River Mouth, Yotsugawa, Adogawa, Shiga (P) & Svm & 10 & - & & P1691 \\
\hline & \multirow[t]{2}{*}{3 Ado R. Mouth, Kitafunaki, Adogawa, Shiga (P) } & Svm & 21 & 16 & P9 & P1284 \\
\hline & & $\mathrm{Sb}$ & 1 & - & & P1294 \\
\hline & 4 Off Imazu, Shiga (P) & Svm & 10 & - & & P1692 \\
\hline & \multirow[t]{2}{*}{5 Off Momose, Chinai, Makino, Shiga (P) } & Svm & 21 & 16 & P10 & P1286 \\
\hline & & $\mathrm{Sb}$ & 2 & - & & P1293 \\
\hline & 6 Off Oura, Nishiazai, Shiga (P) & Svm & 25 & - & R2 & P1281 \\
\hline & \multirow[t]{2}{*}{7 Around off Onoe, Kohoku, Shiga (P\&R) } & Svm & 26 & 32 & P1, R1 & P1279, 1280 \\
\hline & & $\mathrm{Sb}$ & 17 & 20 & $\mathrm{BN}$ & P1295, 1296 \\
\hline & 8 Off Minamiham, Nagahama, Shiga (P) & Svm & 12 & - & P2 & P1289 \\
\hline & 9 Tributary of Ane R., Bessho, Kohoku, Shiga (P) & Svm & 12 & - & & P1693 \\
\hline & 10 Around Takeshima Island, Off Hikone, Shiga (P) & Svm & 25 & 22 & P3 & P1287 \\
\hline & 11 Channel, Ryohama, Hikone, Shiga (P) & Svm & 10 & - & & P1694 \\
\hline & 12 Off Notogawa, Notogawa, Shiga (P) & Svm & 9 & - & P4 & P1283 \\
\hline & 13 Around Okishima Is., Off Oumihachiman, Shiga (R) & Svm & - & 9 & R3 & \\
\hline & \multirow{2}{*}{14 Off Mizugahama, Oumihachiman, Shiga (R) } & Svm & 11 & 16 & R5 & P1290 \\
\hline & & $\mathrm{Sb}$ & 7 & $8^{b}$ & $\mathrm{BE}$ & P1292 \\
\hline & 15 Off Chuzu, Yasu, Shiga (P) & Svm & 10 & 9 & P5 & P1285 \\
\hline & 16 Off Moriyama, Shiga (P) & Svm & 10 & 8 & P6 & P1282 \\
\hline & 17 Off Shimosakamoto, Otsu, Shiga (P) & Svm & 10 & 10 & P7 & P1288 \\
\hline \multicolumn{7}{|c|}{ Ise Bay area } \\
\hline & 18 Hijie R., Ibi R. s., Tado, Kuwana, Mie & Svv & 3 & - & & P1695 \\
\hline & 19 Harai R., Kushida R. S., Matsusaka, Mie & Svv & 19 & 15 & & P1696 \\
\hline \multicolumn{7}{|l|}{ Kinki } \\
\hline & 20 Kizu R., Yodo R. S., Kyotanabe, Kyoto & Svv & 4 & - & & P1697 \\
\hline & 21 Yura R., Ayabe, Kyoto & Svv & 20 & 20 & & P1698 \\
\hline & 22 Muko R., Sasayama, Hyogo & Svv & 10 & 11 & & P1699 \\
\hline & 23 Maruyama R., Toyooka, Hyogo & Svv & 2 & - & & P1700 \\
\hline \multicolumn{7}{|l|}{ Chugoku } \\
\hline & 24 Takahashi R., Kurashiki, Okayama & Svv & 4 & - & & P1701 \\
\hline & 25 Ashida R., Fukuyama, Hiroshima & Svv & 14 & 19 & & P1702 \\
\hline & 26 Hii R., Unnan, Shimane & Svv & 3 & - & & P1703 \\
\hline \multicolumn{7}{|l|}{ Kyushu } \\
\hline & 27 Naka R., Fukuoka, Fukuoka & Svv & 8 & 8 & & P1704 \\
\hline & 28 Futatsu R., Yanagawa, Fukuoka & Svv & 8 & - & & P1705 \\
\hline
\end{tabular}

Bottom type for Lake Biwa; $P$ pebbly, $R$ rocky

GEDIMAP: http://gedimap.zool.kyoto-u.ac.jp

Svm, S. variegatus microoculus; Sb, S. biwaensis; Svv, S. variegatus variegatus

a Data fully or partially from Komiya et al. (2011) and sample codes in the reference

${ }^{\mathrm{b}}$ Specimens from the captive population kept in Lake Biwa Museum, except two specimens for microsatellite analysis 
Table 2 Genetic diversity of the regional population groups of the Japanese Sarcocheilichthys fishes

\begin{tabular}{|c|c|c|c|c|c|c|c|c|c|c|c|}
\hline \multirow{2}{*}{ Region } & \multirow{2}{*}{$\begin{array}{l}\text { Number of local } \\
\text { samples }\end{array}$} & \multirow{2}{*}{$\begin{array}{l}\text { Number of total } \\
\text { specimens }\end{array}$} & \multirow{2}{*}{$\begin{array}{l}\text { Total number } \\
\text { of haplotypes }\end{array}$} & \multicolumn{5}{|c|}{ Proportion of each clade (number of haplotypes) } & \multirow{2}{*}{$\begin{array}{l}\text { Haplotype richness } \\
\text { at } n=16(95 \% \mathrm{Cl})\end{array}$} & \multirow{2}{*}{ Haplotype diversty ( \pm SE) } & \multirow{2}{*}{ Nucleotide diversiy $\times 100( \pm$ SE) } \\
\hline & & & & A & B & C & $\mathrm{D}$ & $\mathrm{E}$ & & & \\
\hline \multicolumn{12}{|c|}{ S. variegatus microoculus } \\
\hline Lake Biwa & 15 & 222 & 22 & $0.89(16)$ & $0.05(3)$ & $0.06(3)$ & - & - & $4.67(2-7)$ & $0.4513 \pm 0.0425$ & $0.3220 \pm 0.2018$ \\
\hline \multicolumn{12}{|l|}{ S. biwaensis } \\
\hline Lake Biwa & 4 & 27 & 6 & $0.93(4)$ & $0.07(2)$ & - & - & - & $4.63(3-6)$ & $0.5442 \pm 0.1058$ & $0.2270 \pm 0.1598$ \\
\hline \multicolumn{12}{|l|}{ S. v. variegatus } \\
\hline Ise Bay area & 2 & 22 & 4 & - & - & - & - & $1.00(4)$ & $3.16(2-4)$ & $0.2597 \pm 0.1202$ & $0.1159 \pm 0.1006$ \\
\hline Kinki & 4 & 36 & 11 & $0.19(1)$ & $0.36(6)$ & $0.08(1)$ & $0.36(3)$ & - & $8.43(6-10)$ & $0.9000 \pm 0.0236$ & $0.9240 \pm 0.5035$ \\
\hline Chugoku & 3 & 21 & 7 & $0.57(3)$ & $0.33(3)$ & $0.10(1)$ & - & - & $6.47(5-7)$ & $0.8476 \pm 0.0440$ & $0.9892 \pm 0.5471$ \\
\hline Kyushu & 2 & 16 & 1 & - & - & $1.00(1)$ & - & - & $1.00(1-1)$ & 0 & 0 \\
\hline
\end{tabular}

Regions correspond to those in Table 1 
Table 3 Estimated divergence times of the major clades of the Japanese Sarcocheilichthys fishes

\begin{tabular}{clcc}
\hline Node & & tMRCA (mean \pm SE) & $95 \%$ HPD \\
\hline 1 & Clade A & $0.457 \pm 0.009$ & $0.208-0.793$ \\
2 & Clade B & $0.429 \pm 0.007$ & $0.181-0.746$ \\
3 & Clade C & $0.473 \pm 0.007$ & $0.165-0.839$ \\
4 & Clade D & $0.178 \pm 0.003$ & $0.027-0.375$ \\
5 & Clade E & $0.286 \pm 0.003$ & $0.075-0.504$ \\
6 & Clades A + D & $0.616 \pm 0.012$ & $0.286-1.083$ \\
7 & Clades A + D + B & $0.750 \pm 0.013$ & $0.384-1.239$ \\
8 & Clades A-D & $0.811 \pm 0.013$ & $0.455-1.292$ \\
Cs & Clades A-E (all) & $1.262 \pm 0.000$ & $1.017-1.510$ \\
\hline
\end{tabular}

Node codes correspond to those in Fig. 3

Cs the node given the constraint of 1.1-1.5 Mya (see "Materials and methods") 

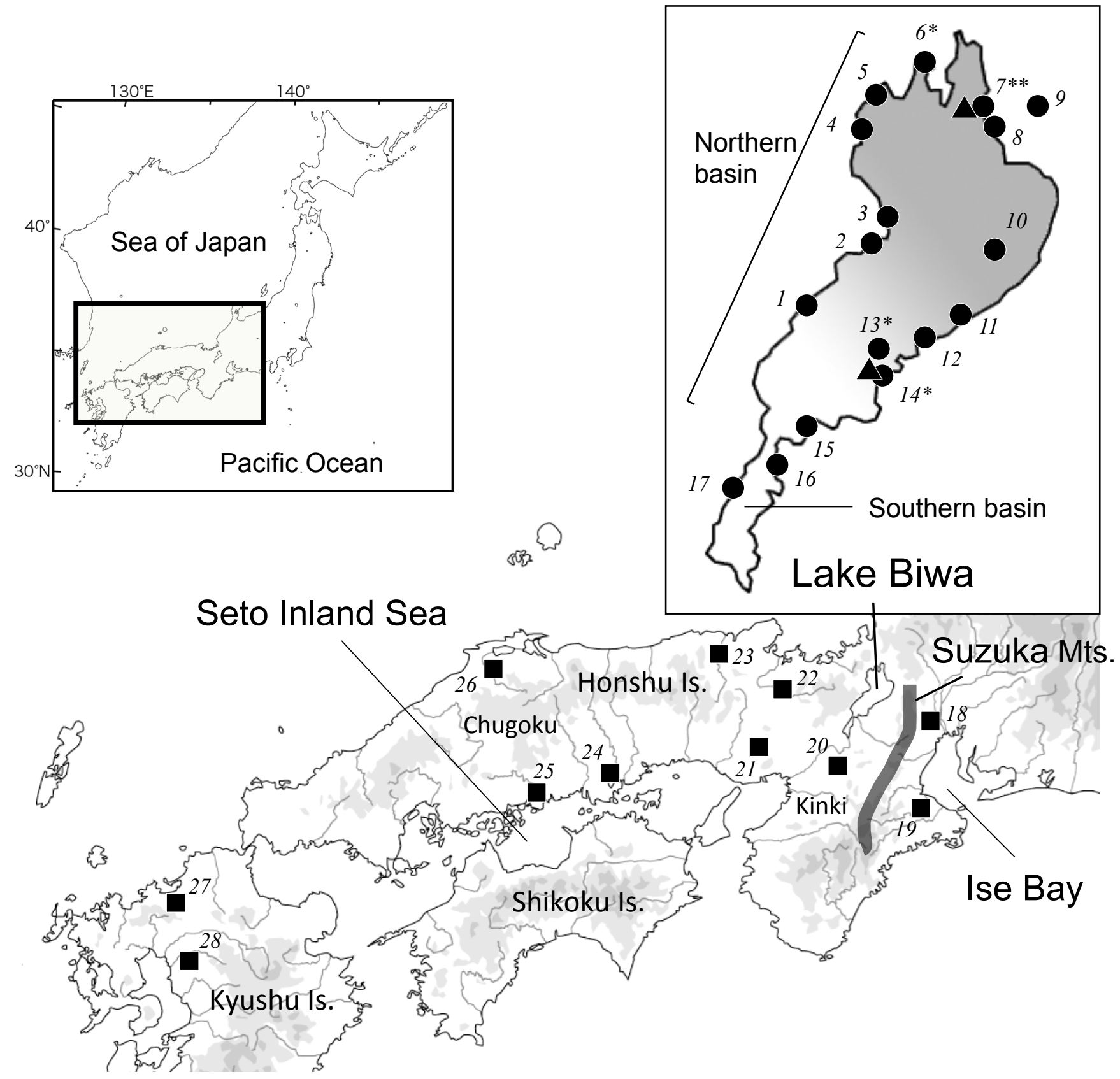


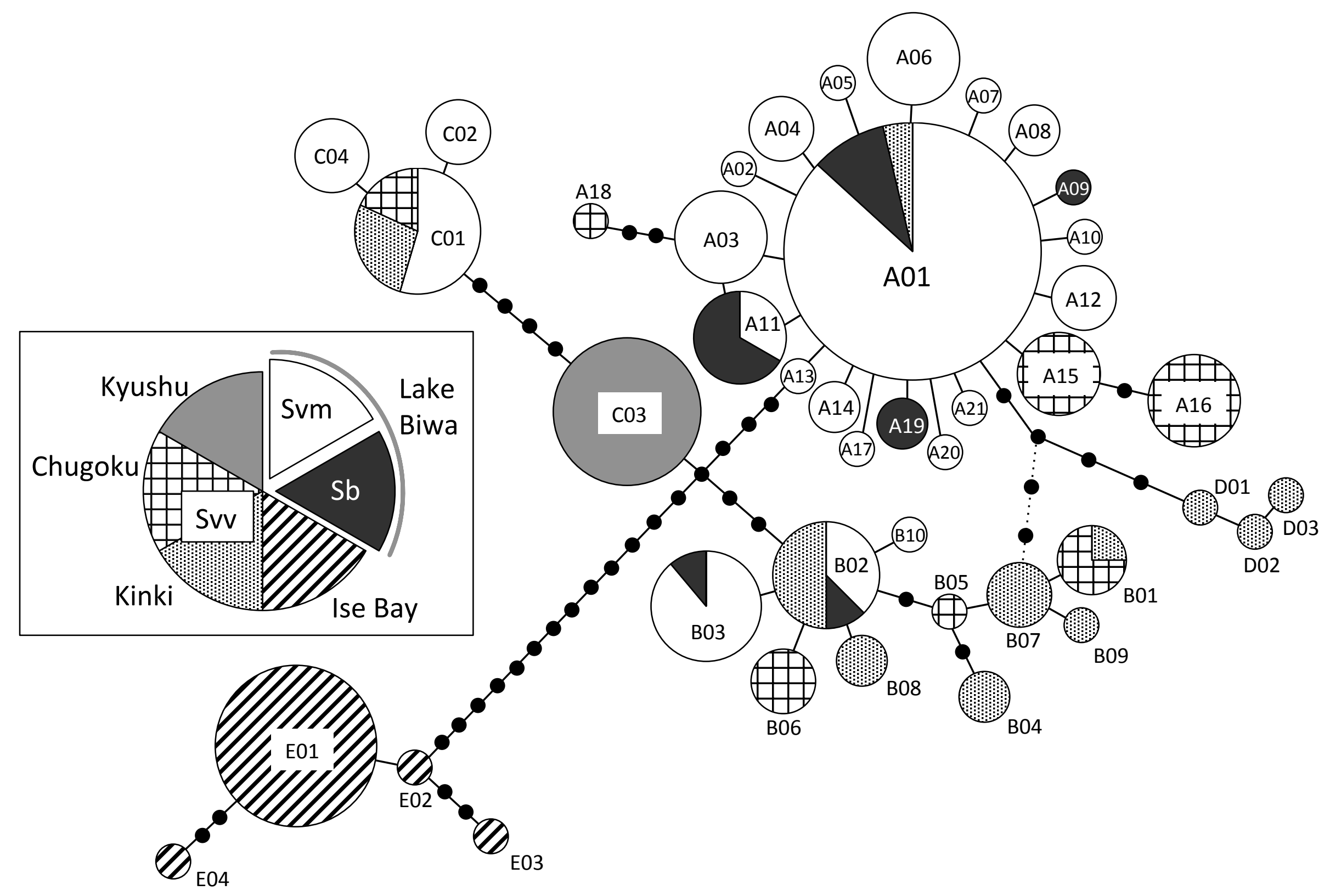

Fig. 2 


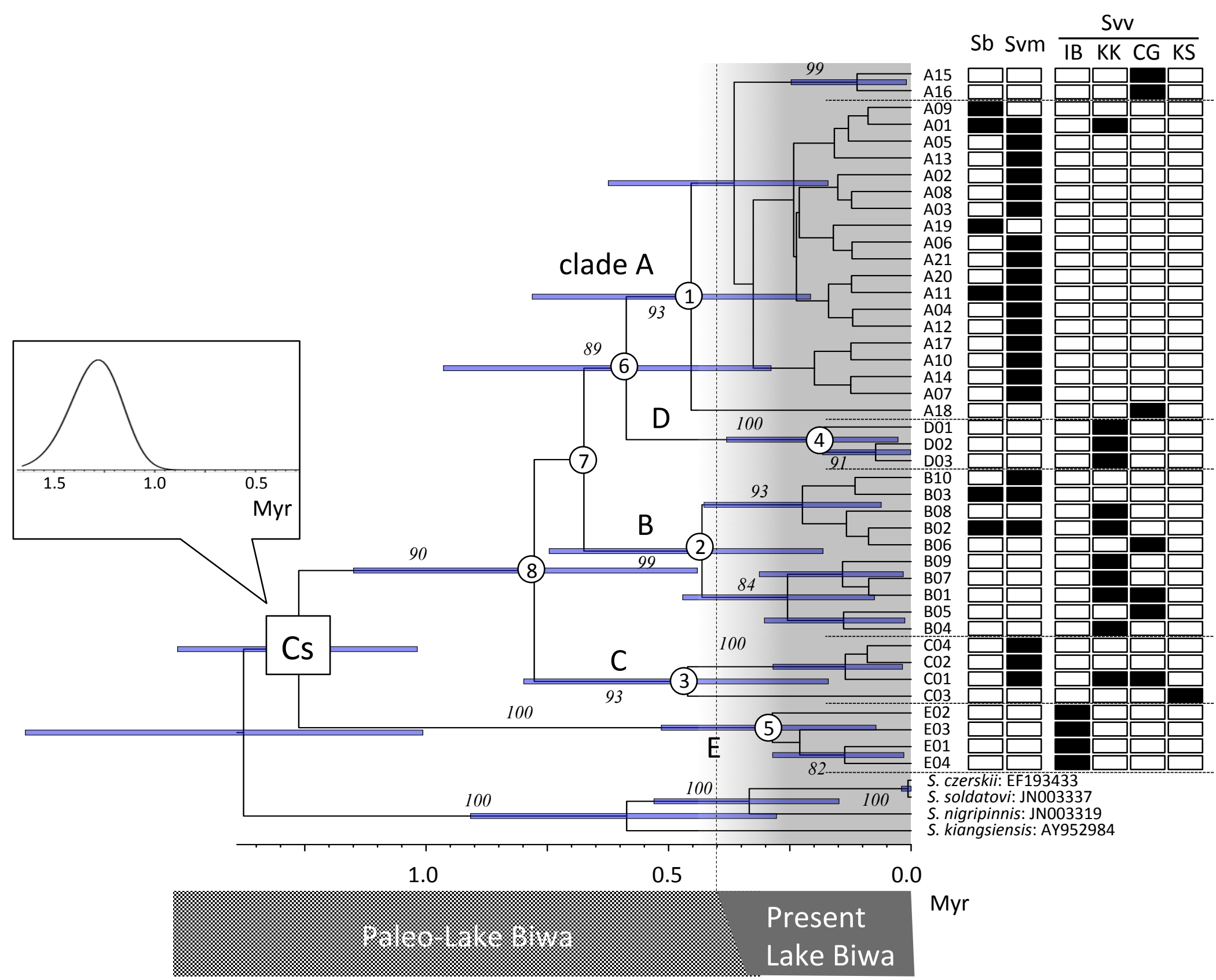

Fig. 3 

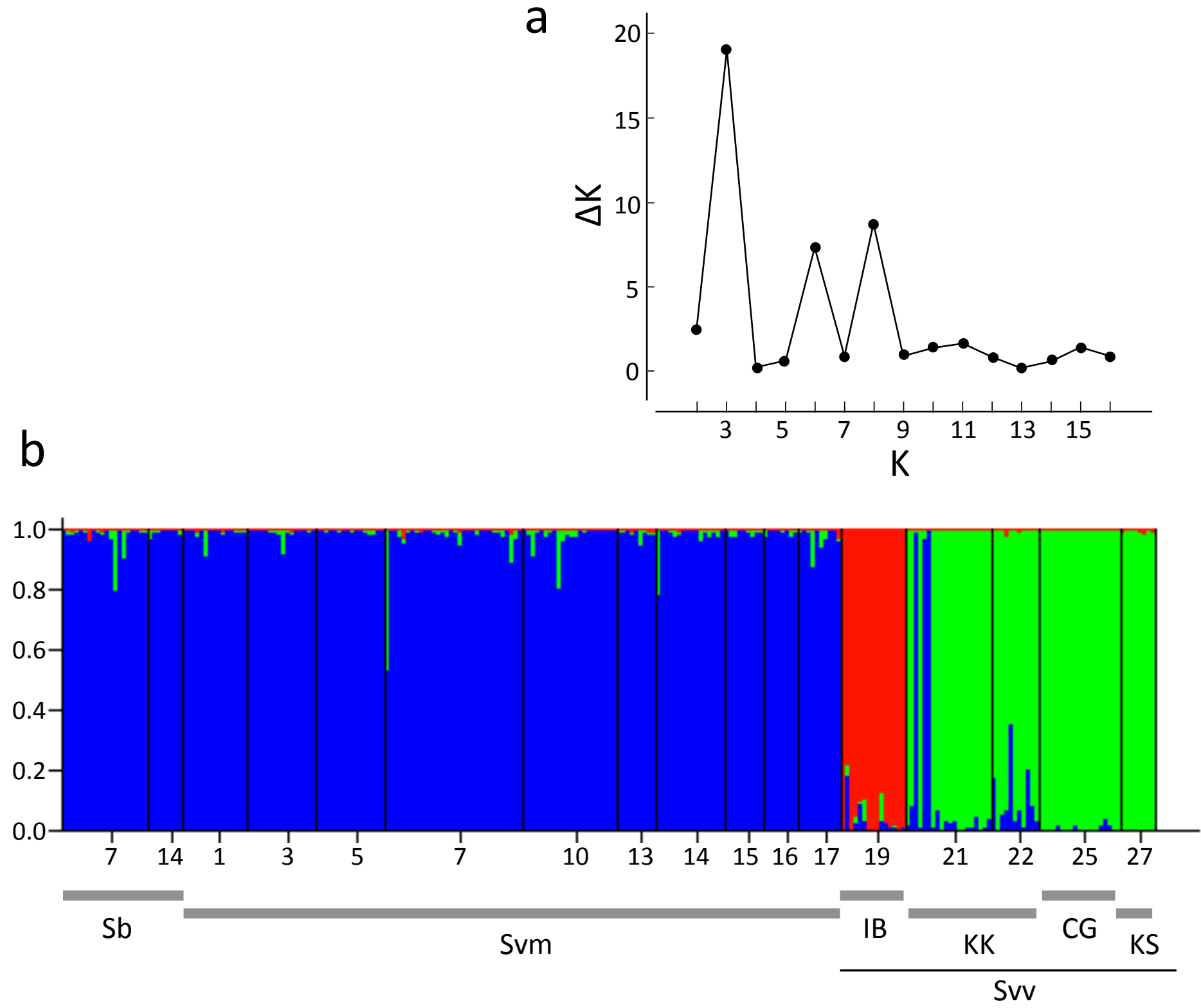

Fig. 4 

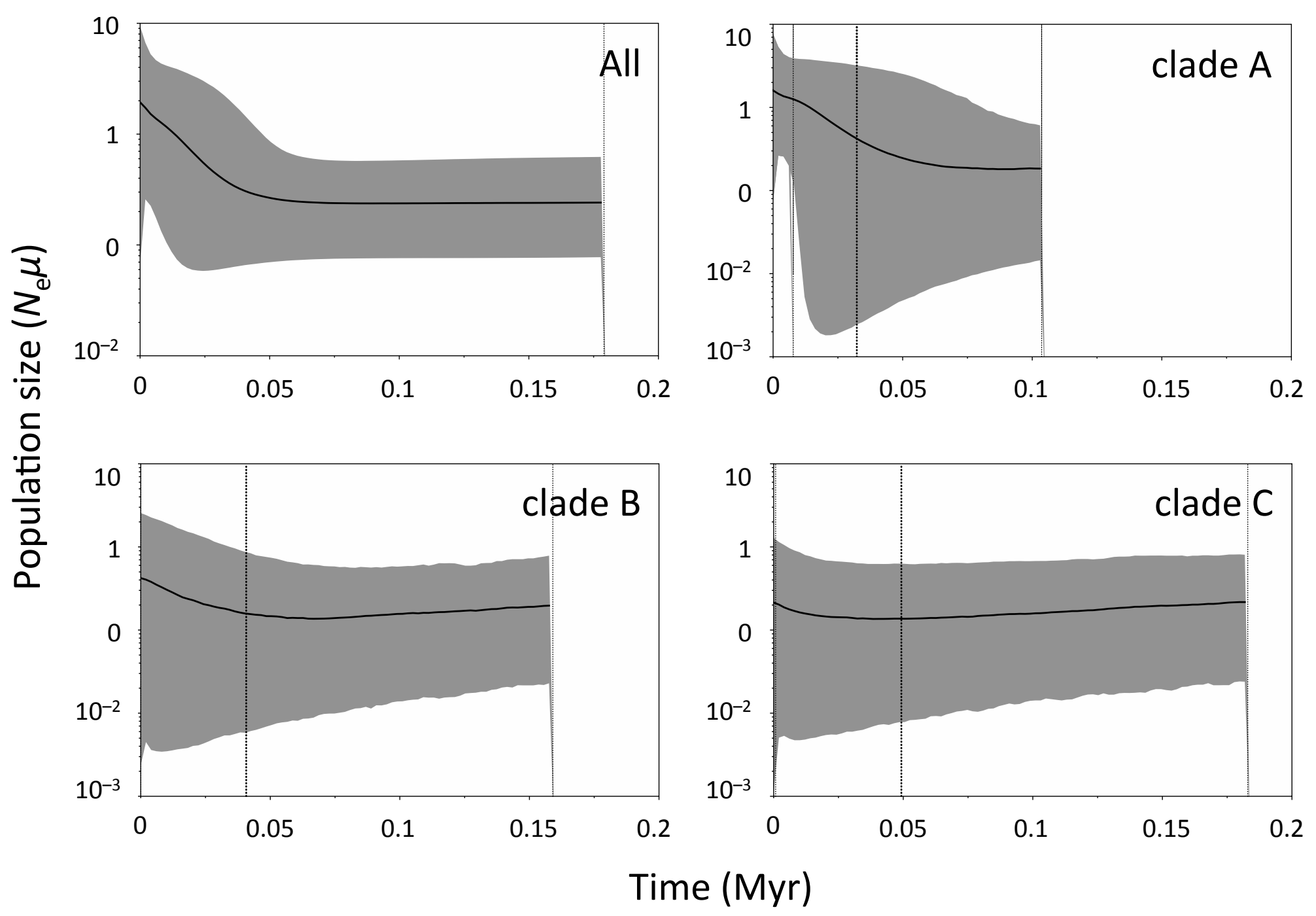

Fig. 5 
a
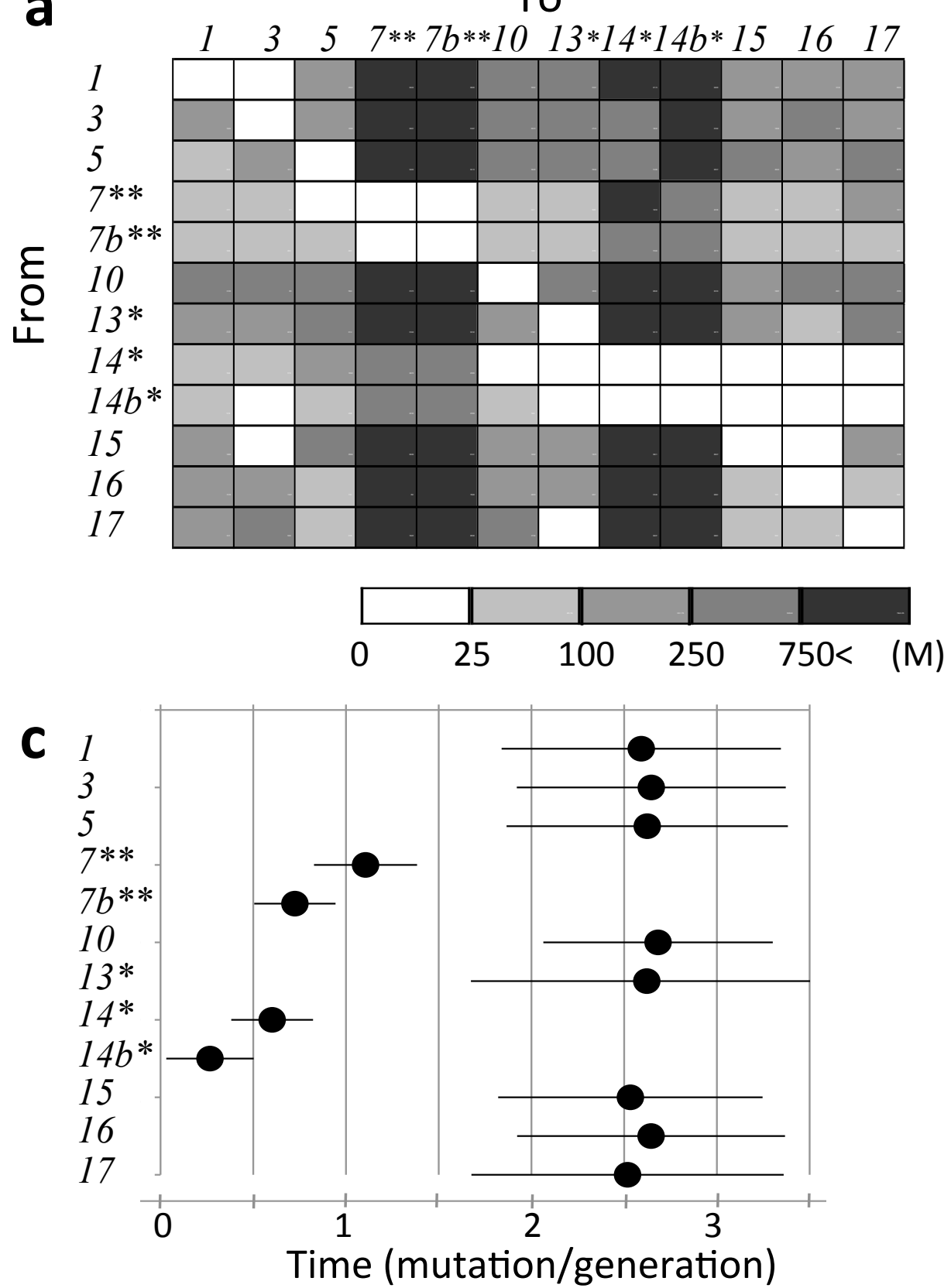

b

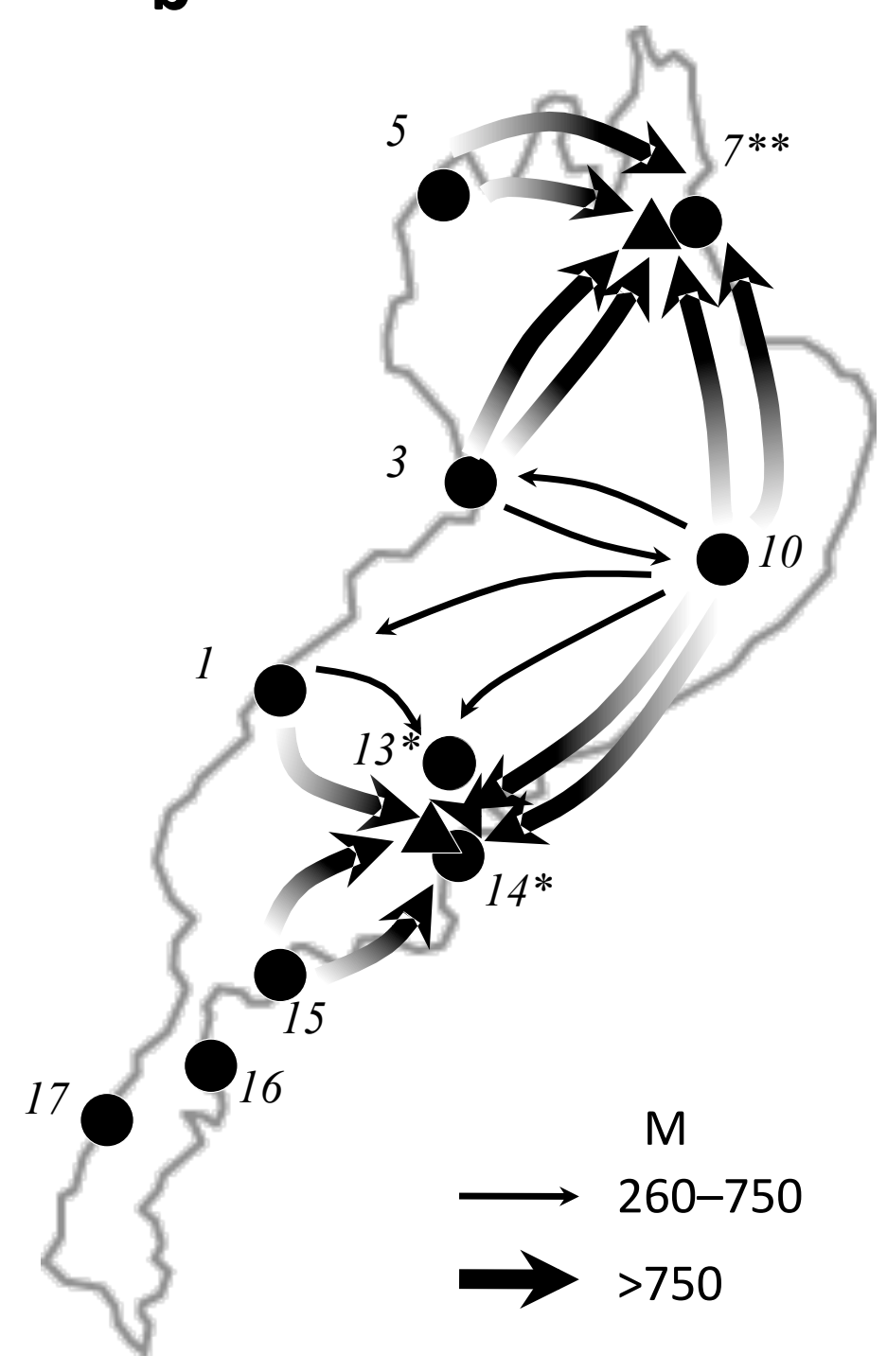

Fig. 6 
ESM Table S1 Average expected heterozygosity ( $\pm S D$ ) and number of loci that showed the deviation from Hardy-Weinberg equilibrium

\begin{tabular}{|c|c|c|c|c|c|}
\hline Locality code & Locality & Species & $\begin{array}{l}\text { Number of } \\
\text { specimens }\end{array}$ & $\begin{array}{l}\text { Average expected } \\
\text { heterozygosity }\end{array}$ & $\mathrm{H}-\mathrm{W}-\mathrm{E}$ deviation ${ }^{\mathrm{a}}$ \\
\hline \multicolumn{6}{|l|}{ Lake Biwa } \\
\hline & 1 Off Kitakomatsu, Otsu, Shiga & Svm & 15 & $0.7378 \pm 0.3843$ & 0 \\
\hline & 3 Ado R. Mouth, Kitafunaki, Adogawa, Shiga & Svm & 16 & $0.7098 \pm 0.3700$ & 0 \\
\hline & 5 Off Momose, Chinai, Makino, Shiga & Svm & 16 & $0.7216 \pm 0.3756$ & 0 \\
\hline & 7 Off Onoe, Kohoku, Shiga & Svm & 32 & $0.7316 \pm 0.3747$ & 0 \\
\hline & & $\mathrm{Sb}$ & 20 & $0.7462 \pm 0.3852$ & 0 \\
\hline & 10 Around Takeshima Island, Off Hikone, Shiga & Svm & 22 & $0.7265 \pm 0.3749$ & 0 \\
\hline & 13 Around Okishima Is., Off Oumihachiman, Shiga & Svm & 9 & $0.7208 \pm 0.3846$ & 0 \\
\hline & 14 Off Mizugahama, Oumihachiman, Shiga & Svm & 16 & $0.7111 \pm 0.3705$ & 0 \\
\hline & & $\mathrm{Sb}$ & 8 & $0.6839 \pm 0.3689$ & 0 \\
\hline & 15 Off Chuzu, Yasu, Shiga & Svm & 9 & $0.7330 \pm 0.3907$ & 0 \\
\hline & 16 Off Moriyama, Shiga & Svm & 8 & $0.7226 \pm 0.3884$ & 0 \\
\hline & 17 Off Shimosakamoto, Otsu, Shiga & Svm & 10 & $0.7090 \pm 0.3766$ & 0 \\
\hline \multicolumn{6}{|c|}{ Ise Bay area } \\
\hline & 19 Harai R., Kushida R. S., Matsusaka, Mie & Svv & 15 & $0.3956 \pm 0.2171$ & 1 \\
\hline \multicolumn{6}{|l|}{ Kinki } \\
\hline & 21 Yura R., Ayabe, Kyoto & Svv & 20 & $0.7522 \pm 0.3881$ & 3 \\
\hline & 22 Muko R., Sasayama, Hyogo & Svv & 11 & $0.7443 \pm 0.3922$ & 0 \\
\hline \multicolumn{6}{|l|}{ Chugoku } \\
\hline & 25 Ashida R., Fukuyama, Hiroshima & Svv & 19 & $0.7833 \pm 0.4037$ & 0 \\
\hline \multicolumn{6}{|l|}{ Kyushu } \\
\hline & 27 Naka R., Fukuoka, Fukuoka & Svv & 8 & $0.4893 \pm 0.2709$ & 0 \\
\hline
\end{tabular}

Svm, S. variegatus microoculus; Sb, S. biwaensis; Svv, S. variegatus variegatus

${ }^{a}$ Number of loci that showed significant deviation from Hardy-Weinberg equilibrium $(P<0.05$ after sequencial Bonferroni correction by each sample, $n=14$ loci) 
ESM Table S2 Matrix of geographical distances as shorter coastal distances (km) for "geofile" in Migrate-n analysis

\begin{tabular}{|c|c|c|c|c|c|c|c|c|c|c|c|c|}
\hline \multirow[b]{2}{*}{ Samples } & \multicolumn{12}{|l|}{ Samples } \\
\hline & 1 & 3 & 5 & 7 & $7 \mathrm{~b}$ & 10 & 13 & 14 & $14 b$ & 15 & 16 & 17 \\
\hline 1 Off Kitakomatsu, Otsu, Shiga & - & & & & & & & & & & & \\
\hline 3 Ado R. Mouth, Kitafunaki, Adogawa, Shiga & 12.5 & & & & & & & & & & & \\
\hline 5 Off Momose, Chinai, Makino, Shiga & 31.9 & 19.4 & & & & & & & & & & \\
\hline 7 Off Onoe, Kohoku, Shiga & 72.4 & 59.9 & 40.5 & & & & & & & & & \\
\hline 7b Off Onoe, Kohoku, Shiga & 72.4 & 59.9 & 40.5 & 0.0 & & & & & & & & \\
\hline 10 Around Takeshima Island, Off Hikone, Shiga & 63.7 & 76.2 & 74.7 & 34.2 & 34.2 & & & & & & & \\
\hline 13 Around Okishima Is., Off Oumihachiman, Shiga & 42.5 & 55.0 & 74.4 & 50.6 & 50.6 & $27.0-$ & & & & & & \\
\hline 14 Off Mizugahama, Oumihachiman, Shiga & 39.6 & 52.1 & 71.5 & 47.7 & 47.7 & 24.1 & $2.9-$ & & & & & \\
\hline 14b Off Mizugahama, Oumihachiman, Shiga & 39.6 & 52.1 & 71.5 & 47.7 & 47.7 & 24.1 & 2.9 & 0.0 & & & & \\
\hline 15 Off Chuzu, Yasu, Shiga & 25.2 & 37.7 & 57.1 & 62.1 & 62.1 & 38.5 & 17.3 & 14.4 & 14.4 & & & \\
\hline 16 Off Moriyama, Shiga & 22.0 & 34.5 & 53.9 & 68.3 & 68.3 & 44.7 & 23.5 & 20.6 & 20.6 & $6.2-$ & & \\
\hline 17 Off Shimosakamoto, Otsu, Shiga & 27.2 & 39.7 & 59.1 & 73.5 & 73.5 & 49.9 & 28.7 & 25.8 & 25.8 & 11.4 & $6.0-$ & \\
\hline
\end{tabular}

Samples $7 \mathrm{~b}$ and $14 \mathrm{~b}$ are of Sarcocheilichthys biwaensis; others S. variegatus microoculus 
ESM Table 33 Pairwise $F_{5}$ for the Sarcocheilichthys samples with sample sizes $\geq 8$ based on mtDNA and microsatellite data

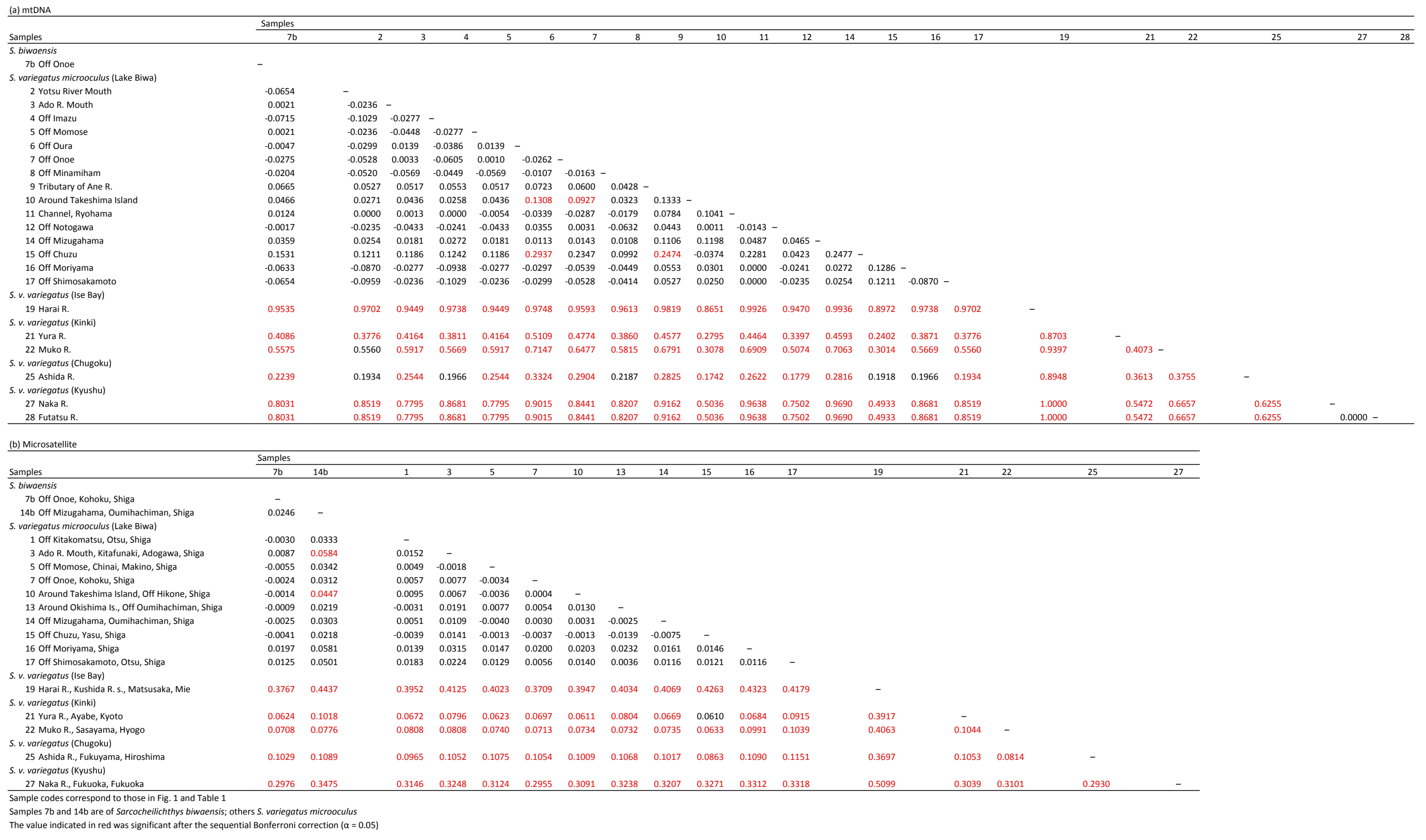


ESM Table S4 Results of mismatch distribution analysis and neutrality tests by Tajima's $D$ and Fu's $F_{5}$ for pooled and respective samples of Sarcocheilichthys species

\begin{tabular}{|c|c|c|c|c|c|c|c|c|c|c|c|c|c|c|c|c|c|}
\hline \multirow[b]{2}{*}{ Region } & \multirow[b]{2}{*}{ Code } & \multirow[b]{2}{*}{ Population/clade } & \multirow[b]{2}{*}{ Bottom type } & \multirow[b]{2}{*}{ Species } & \multirow[b]{2}{*}{$n$} & \multicolumn{4}{|c|}{ Sudden expansion model } & \multicolumn{4}{|c|}{ Spatial expansion model } & \multirow[b]{2}{*}{ Tajima's $D$} & \multirow[b]{2}{*}{$P$} & \multirow[b]{2}{*}{ Fu's $F_{s}$} & \multirow[b]{2}{*}{$P$} \\
\hline & & & & & & $\tau ; 95 \%$ C.I. & $\vartheta_{0}$ & $\theta_{1}$ & $P(\mathrm{SSD})$ & $\tau ; 95 \%$ C.I. & $\vartheta$ & M & $P(S S D)$ & & & & \\
\hline \multirow[t]{23}{*}{ Lake Biwa } & & & & & & & & & & & & & & & & & \\
\hline & $2-12,14-17$ & Lake Biwa (all) & P\&R & Svm & 222 & $\begin{array}{l}0.039 \\
0.002-0.543\end{array}$ & 0.000 & inf. & $<0.001$ & $\begin{array}{l}8.540 \\
0.001-63.356\end{array}$ & 0.582 & 0.239 & 0.649 & -1.543 & 0.031 & -9.231 & 0.008 \\
\hline & $3,5,7,14$ & Lake Biwa (all) & P\&R & sb & 27 & $\begin{array}{l}0.703 \\
0.201-1.367\end{array}$ & 0.000 & inf. & 0.113 & $\begin{array}{l}0.692 \\
0.247-1.532\end{array}$ & 0.011 & inf. & 0.046 & -1.484 & 0.054 & -0.789 & 0.323 \\
\hline & & Clade A & P\&R & Svm & 195 & $\begin{array}{l}3.000 \\
0.000-3.500\end{array}$ & 0.000 & 0.460 & 0.431 & $\begin{array}{l}0.374 \\
0.206-0.601\end{array}$ & 0.001 & inf. & 0.025 & -2.168 & $<0.001$ & -23.360 & $<0.001$ \\
\hline & & Clade B & P\&R & Svm & 12 & $\begin{array}{l}0.768 \\
0.000-1.885\end{array}$ & 0.000 & inf. & 0.781 & $\begin{array}{l}0.751 \\
0.082-2.324\end{array}$ & 0.016 & inf. & 0.573 & -0.047 & 0.442 & -0.137 & 0.338 \\
\hline & & Clade C & P\&R & Svm & 13 & $\begin{array}{l}1.074 \\
0.000-2.236\end{array}$ & 0.000 & inf. & 0.153 & $\begin{array}{l}1.073 \\
0.324-2.353\end{array}$ & 0.001 & inf. & 0.092 & 0.879 & 0.819 & 0.436 & 0.556 \\
\hline & 2 & Yotsu R. mouth, Adogawa & $\mathrm{P}$ & Svm & 10 & $\begin{array}{l}3.000 \\
0.457-3.807\end{array}$ & 0.000 & 0.499 & 0.230 & $\begin{array}{l}7.549 \\
0.000-98.222\end{array}$ & 0.366 & 0.267 & 0.470 & -1.873 & 0.007 & 1.453 & 0.794 \\
\hline & 3 & Ado R. mouth, Kitafunaki & $\mathrm{P}$ & Svm & 21 & $\begin{array}{l}3.000 \\
0.410-3.000\end{array}$ & 0.000 & 0.272 & 0.104 & $\begin{array}{l}10.743 \\
0.000-170.500\end{array}$ & 0.140 & 0.252 & 0.356 & -1.510 & 0.052 & 1.735 & 0.831 \\
\hline & 4 & Off Imazu & $\mathrm{P}$ & Svm & 10 & $\begin{array}{l}3.000 \\
0.430-3.000\end{array}$ & 0.000 & 0.133 & 0.034 & $\begin{array}{l}7.712 \\
0.000-170.625\end{array}$ & 0.001 & 0.277 & 0.308 & -1.839 & 0.010 & 2.985 & 0.911 \\
\hline & 5 & Off Momose & $\mathrm{P}$ & Svm & 21 & $\begin{array}{l}3.250 \\
0.000-46.250\end{array}$ & 0.330 & 0.630 & 0.259 & $\begin{array}{l}9.490 \\
0.000-109.286\end{array}$ & 0.532 & 0.217 & 0.429 & -1.510 & 0.051 & 0.645 & 0.670 \\
\hline & 6 & Off Oura & $\mathrm{P}$ & Svm & 25 & $\begin{array}{l}3.000 \\
0.344-3.574\end{array}$ & 0.000 & 0.397 & 0.392 & $\begin{array}{l}7.708 \\
0.000-85.000\end{array}$ & 0.366 & 0.067 & 0.431 & -2.160 & 0.002 & -1.431 & 0.118 \\
\hline & 7 & Around off Onoe & P\&R & Svm & 26 & $\begin{array}{l}3.250 \\
0.121-4.746\end{array}$ & 0.330 & 0.623 & 0.411 & $\begin{array}{l}7.148 \\
0.000-89.775\end{array}$ & 0.548 & 0.153 & 0.519 & -1.693 & 0.028 & -1.152 & 0.211 \\
\hline & & & & sb & 17 & $\begin{array}{l}0.594 \\
0.000-2.393\end{array}$ & 0.000 & 188.438 & 0.768 & $\begin{array}{l}7.021 \\
0.000-183.75\end{array}$ & 0.740 & 0.274 & 0.495 & -1.195 & 0.116 & 0.114 & 0.553 \\
\hline & 8 & Off Minamihama & $\mathrm{P}$ & Svm & 12 & $\begin{array}{l}0.500 \\
0.000-0.093\end{array}$ & 0.000 & inf. & 0.193 & $\begin{array}{l}9.460 \\
0.000-112.424\end{array}$ & 0.647 & 0.179 & 0.464 & -2.067 & 0.003 & 0.717 & 0.656 \\
\hline & 9 & Ane R., Kohoku & $\mathrm{P}$ & Svm & 12 & $\begin{array}{l}1.117 \\
0.000-2.289\end{array}$ & 0.000 & inf. & 0.140 & $\begin{array}{l}1.114 \\
0.373-2.454\end{array}$ & 0.003 & inf. & 0.080 & -0.379 & 0.367 & -0.895 & 0.137 \\
\hline & 10 & Takeshima Is. & $\mathrm{P}$ & Svm & 25 & $\begin{array}{l}9.529 \\
0.096-95.529\end{array}$ & 0.000 & 2.644 & 0.177 & $\begin{array}{l}8.338 \\
0.437-19.617\end{array}$ & 0.680 & 1.173 & 0.720 & 0.130 & 0.601 & 0.961 & 0.701 \\
\hline & 11 & Hikone & $\mathrm{P}$ & Svm & 10 & $\begin{array}{l}0.490 \\
0.000-1.367\end{array}$ & 0.000 & inf. & 0.457 & $\begin{array}{l}0.475 \\
0.000-2.323\end{array}$ & 0.014 & inf. & 0.350 & -1.401 & 0.034 & -1.164 & 0.037 \\
\hline & 12 & Off Notogawa & $\mathrm{P}$ & Svm & 9 & $\begin{array}{l}1.217 \\
0.000-2.643\end{array}$ & 0.000 & inf. & 0.180 & $\begin{array}{l}10.411 \\
0.000-116.660\end{array}$ & 2.132 & 0.222 & 0.120 & -1.723 & 0.027 & 0.087 & 0.505 \\
\hline & 14 & Off Mizugahama & $\mathrm{R}$ & Svm & 11 & $\begin{array}{l}0.436 \\
0.000-1.232\end{array}$ & 0.000 & inf. & 0.444 & $\begin{array}{l}0.432 \\
0.000-48.125\end{array}$ & 0.004 & inf. & 0.273 & -0.100 & 0.331 & 0.356 & 0.366 \\
\hline & & & & sb & 7 & $\begin{array}{l}0.898 \\
0.000-22.750\end{array}$ & 0.000 & inf. & 0.284 & $\begin{array}{l}0.898 \\
0.000-101.190\end{array}$ & 0.001 & inf. & 0.223 & 1.342 & 0.972 & 0.856 & 0.604 \\
\hline & 15 & Off Chuzu & $\mathrm{P}$ & Svm & 10 & $\begin{array}{l}10.203 \\
0.314-99.203\end{array}$ & 0.002 & 11.437 & 0.084 & $\begin{array}{l}8.573 \\
0.455-36.388\end{array}$ & 1.185 & 1.944 & 0.469 & 0.479 & 0.719 & 1.806 & 0.816 \\
\hline & 16 & Off Moriyama & $\mathrm{P}$ & Svm & 10 & $\begin{array}{l}3.000 \\
0.457-3.801\end{array}$ & 0.000 & 0.504 & 0.244 & $\begin{array}{l}6.548 \\
0.000-100.111\end{array}$ & 0.361 & 0.272 & 0.479 & -1.839 & 0.008 & 1.160 & 0.767 \\
\hline & 17 & Off Shimosakamoto & $\mathrm{P}$ & Svm & 10 & $\begin{array}{l}3.000 \\
0.457-3.836\end{array}$ & 0.000 & 0.499 & 0.248 & $\begin{array}{l}7.550 \\
0.000-103.889\end{array}$ & 0.366 & 0.267 & 0.480 & -1.873 & 0.006 & 1.453 & 0.800 \\
\hline Ise Bay & 19 & Harai R., Mie & & Svv & 19 & - & & & & - & & & & 0.000 & & - & \\
\hline \multirow[t]{2}{*}{ Kinki } & 21 & Yura R., Kyoto & & Swv & 20 & $\begin{array}{l}10.516 \\
0.000-16.887\end{array}$ & 0.000 & 6.231 & 0.514 & $\begin{array}{l}6.916 \\
0.397-22.933\end{array}$ & 2.773 & 1.197 & 0.691 & 0.048 & 0.570 & 2.573 & 0.877 \\
\hline & 22 & Muko R., Hyogo & & Svv & 10 & $\begin{array}{l}4.770 \\
0.410-8.551\end{array}$ & 0.000 & 6.417 & 0.492 & $\begin{array}{l}2.986 \\
0.577-8.247\end{array}$ & 1.335 & 4.248 & 0.494 & -0.250 & 0.416 & 0.322 & 0.559 \\
\hline Chugoku & 25 & Ashida R., Hiroshima & & Swv & 14 & $\begin{array}{l}9.562 \\
0.000-98.562\end{array}$ & 0.000 & 9.727 & 0.053 & $\begin{array}{l}9.100 \\
4.099-16.662\end{array}$ & 0.001 & 3.723 & 0.073 & 0.637 & 0.770 & 2.527 & 0.887 \\
\hline \multirow[t]{2}{*}{ Kyushu } & 27 & Naka R., Fukuoka & & Svv & 8 & - & & & & - & & & & 0.000 & & - & \\
\hline & 28 & Futatsu R. Fukuoka & & Svv & 8 & - & & & & - & & & & 0.000 & & - & \\
\hline
\end{tabular}

$S b$, S. biwaensis; SVm, S. variegatus microoculus; Svv, S. variegatus variegatus

$\tau$ time parameter with $95 \%$ confidence interval, $\vartheta_{0}$ pre-expansion population size, $\vartheta_{1}$ post-expansion population size, $\vartheta$ population size, $M$ number of migrants exchanged with other demes, inf. infinite, - no result obtained $P(S S D)$ probability for sum of squred deviation by a permutation test 